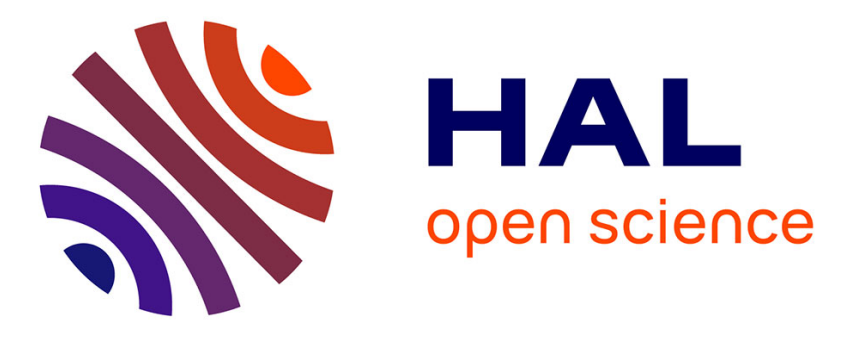

\title{
Simultaneous observations of lower tropospheric continental aerosols with a ground-based, an airborne, and the spaceborne CALIOP lidar system
}

Patrick Chazette, Jean-Christophe Raut, François Dulac, Sébastien Berthier, S.-W. Kim, P. Royer, Joseph Sanak, S. Loaëc, H. Grigaut-Desbrosses

\section{To cite this version:}

Patrick Chazette, Jean-Christophe Raut, François Dulac, Sébastien Berthier, S.-W. Kim, et al.. Simultaneous observations of lower tropospheric continental aerosols with a ground-based, an airborne, and the spaceborne CALIOP lidar system. Journal of Geophysical Research: Atmospheres, 2010, 115 (D4), pp.D00H31. 10.1029/2009JD012341 . hal-00643837

\section{HAL Id: hal-00643837 https://hal.science/hal-00643837}

Submitted on 4 May 2016

HAL is a multi-disciplinary open access archive for the deposit and dissemination of scientific research documents, whether they are published or not. The documents may come from teaching and research institutions in France or abroad, or from public or private research centers.
L'archive ouverte pluridisciplinaire HAL, est destinée au dépôt et à la diffusion de documents scientifiques de niveau recherche, publiés ou non, émanant des établissements d'enseignement et de recherche français ou étrangers, des laboratoires publics ou privés. 


\title{
Simultaneous observations of lower tropospheric continental aerosols with a ground-based, an airborne, and the spaceborne CALIOP lidar system
}

\author{
P. Chazette, ${ }^{1}$ J.-C. Raut, ${ }^{1,2}$ F. Dulac, ${ }^{1}$ S. Berthier, ${ }^{1}$ S.-W. Kim, ${ }^{1}$ P. Royer, ${ }^{1}$ J. Sanak, ${ }^{1}$ \\ S. Loaëc, ${ }^{1}$ and H. Grigaut-Desbrosses ${ }^{1}$ \\ Received 27 April 2009; revised 18 February 2010; accepted 10 March 2010; published 21 August 2010.
}

[1] We present an original experiment with multiple lidar systems operated simultaneously to study the capability of the Cloud-Aerosol LIdar with Orthogonal Polarization (CALIOP), on board the Cloud-Aerosol Lidar Pathfinder Satellite Observation (CALIPSO), to infer aerosol optical properties in the lower troposphere over a midlatitude continental site where the aerosol load is low to moderate. The experiment took place from 20 June to 10 July 2007 in southern France. The results are based on three case studies with measurements coincident to CALIOP observations: the first case study illustrates a large-scale pollution event with an aerosol optical thickness at $532 \mathrm{~nm}\left(\tau_{a 532}\right)$ of $\sim 0.25$, and the two other case studies are devoted to background conditions due to aerosol scavenging by storms with $\tau_{a 532}<0.1$. Our experimental approach involved ground-based and airborne lidar systems as well as Sun photometer measurements when the conditions of observation were favorable. Passive spaceborne instruments, namely the Spinning Enhanced Visible and Infrared Imager (SEVERI) and the Moderate-resolution Imaging Spectroradiometer (MODIS), are used to characterize the large-scale aerosol conditions. We show that complex topographical structures increase the complexity of the aerosol analysis in the planetary boundary layer by CALIOP when $\tau_{a 532}$ is lower than 0.1 because the number of available representative profiles is low to build a mean CALIOP profile with a good signal-to-noise ratio. In a comparison, the aerosol optical properties inferred from CALIOP and those deduced from the other active and passive remote sensing observations in the pollution plume are found to be in reasonable agreement. Level-2 aerosol products of CALIOP are consistent with our retrievals.

Citation: Chazette, P., J.-C. Raut, F. Dulac, S. Berthier, S.-W. Kim, P. Royer, J. Sanak, S. Loaëc, and H. Grigaut-Desbrosses (2010), Simultaneous observations of lower tropospheric continental aerosols with a ground-based, an airborne, and the spaceborne CALIOP lidar system, J. Geophys. Res., 115, D00H31, doi:10.1029/2009JD012341.

\section{Introduction}

[2] The Cloud-Aerosol Lidar Pathfinder Satellite Observation (CALIPSO) orbiting platform [Vaughan et al., 2004; Winker et al., 2007] was inserted in the A-Train constellation behind Aqua on 28 April, 2006 (http://www-calipso. larc.nasa.gov). The CALIPSO payload is composed of the Cloud-Aerosol LIdar with Orthogonal Polarization (CALIOP), the 3-channel Imaging Infrared Radiometer (IIR) and the Wide Field Camera (WFC). We focus here on CALIOP, a nadir-pointing instrument which is built around a diodepumped Nd:YAG laser. One of the main objectives of the CALIOP scientific mission is the study of atmospheric

\footnotetext{
${ }^{1}$ Laboratoire des Sciences du Climat et de l'Environnement, CEA CNRS, UVSQ, Gif-sur-Yvette, France.

${ }^{2}$ Now at Laboratoire Atmosphères, Milieux, Observations Spatiales, CNRS, UVSQ, UPMC, Université Paris 6, Paris, France.

Copyright 2010 by the American Geophysical Union. 0148-0227/10/2009JD012341
}

aerosols. Many experiments have been conducted to validate the level-1 [McGill et al., 2007; Mona et al., 2009] (http:// calipsovalidation.hamptonu.edu) and 2 data products of the instrument [Kim et al., 2008; Ganguly et al., 2009]. The ability to infer aerosol structures and optical properties for desert dust aerosols has been particularly examined due to the important aerosol optical thickness associated with dust events [e.g., Berthier et al., 2006; Cuesta et al., 2008; Uno et al., 2008; Liu et al., 2008; Ben-Ami et al., 2009]. Fewer studies have been conducted to explore the capability of CALIOP to infer the properties of pollution aerosols [e.g., Kim et al., 2008] or biomass burning aerosols [e.g., Labonne et al., 2007; Jeong and Hsu, 2008].

[3] We organized a field experiment over France to evaluate the capability of CALIOP to provide information about continental background and pollution aerosols in midlatitude regions where the atmospheric aerosol load is low or medium. Generally, the aerosol optical thickness at $532 \mathrm{~nm}\left(\tau_{a 532}\right)$ is lower than 0.3 over France [e.g., Hodzic 


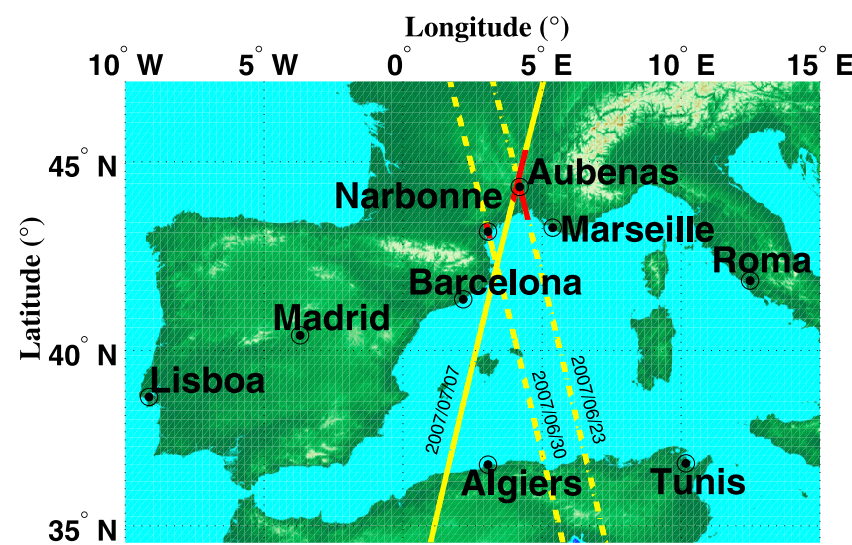

Figure 1. The region in the south of France where the experiment was held. The orbits of interest are indicated in solid and dotted lines for the daytime ( 23 and 30 June 2007 ) and nighttime (6 to 7 July 2007) orbits, respectively. The orbit segments where aerosol optical properties have been extracted are superimposed in red.

et al., 2006]. For example, the mean optical thickness at $532 \mathrm{~nm}$ over Paris area is generally close to 0.15 [Chazette et al., 2005a], larger values being generally observed during large scale heat waves as the one that occurred in August 2003 over Europe [e.g., Lyamania et al., 2006]. Moreover, the challenge was to establish the capability of CALIOP to observe low aerosol layers trapped in the planetary boundary layer (PBL), and eventually above a complex topography. Our goal is mainly to establish the possibility to obtain information on aerosol layers from CALIOP data. It is not necessary with the operational algorithms and we check their limitation in comparing to our own retrieval.

[4] A specific experiment involving both ground and airborne lidar systems was thus scheduled and performed in the south of France from 20 June to 10 July, 2007. The selected area in southeastern France encompassed the region between the Cevennes mountains and the Gulf of Lion (Figure 1). This region was selected because (1) the aerosol load is representative of the lower and medium values that could be encountered over France, (2) it maximized the number of favorable CALIOP orbits during the campaign with varied surface topographies, and (3) it minimized logistical constraints, being closed to the UltraLight Aircraft (ULA) base in Aubenas. Thus, it was relatively straightforward to obtain the necessary authorizations for overflights, and to move mobile systems in the E-W direction from one CALIOP ground track to another. Among the 5 tentative planned intensive observation periods performed simultaneously with CALIOP, only 3 were successful due to meteorological constraints in either a clear atmosphere or pollution conditions. Nevertheless, this approach is complementary to validation measurements captured on groundbased stations [Kim et al., 2008; Pappalardo et al., 2010]. The success rate with satellite coincidence is a function of the meteorological conditions for both approaches. If the ground-based station is very close to the satellite ground track and maintained, the success rate of the ground-based approach is better, all the more so several network stations have been involved. Ground-based stations are not neces- sarily available everywhere and mobile tools are a powerful means to complement the validation plan of CALIOP. This effort is part of a global validation plan of CALIOP which includes measurements from many locations over the world.

[5] This paper presents the results obtained from these three cases where an almost perfect coincidence was obtained with the CALIPSO overflights. The first section presents the lidar systems involved in the experiment. The second section describes additional observations and data used in this work. The third section presents the experimental plan and methodology. The observations in polluted conditions and in a clear atmosphere are discussed in the fourth and fifth sections, respectively. We conclude in a sixth section.

\section{Lidar Instruments}

\subsection{CALIOP}

[6] We focus here on the nadir-pointing lidar system (CALIOP) on-board the CALIPSO satellite. The CALIOP transmitter emits polarized light at both 1064 and $532 \mathrm{~nm}$ with pulse energy of $110 \mathrm{~mJ}$ and a pulse repetition rate of $20.25 \mathrm{~Hz}$. Polarization discrimination in the receiver is performed for the $532 \mathrm{~nm}$ channel [Winker et al., 2004, 2007; Hunt et al., 2009]. Details on the CALIOP instrument, data acquisition, and science products are given by Anselmo et al. [2005] and Winker et al. [2007]. In this work, we use CALIOP data below $8 \mathrm{~km}$ AMSL at the wavelength of $532 \mathrm{~nm}$. The sensitivity of this visible channel to capture aerosol features is increased since it has a better signal-tonoise ratio (SNR) than the infrared channel at $1064 \mathrm{~nm}$. CALIOP level-1 (version 2.01) and -2 data (version 2.01) products are considered. CALIOP level-1 data have different spatial resolutions for different altitude ranges. We consider only the spatial resolution of $\Delta z=30 \mathrm{~m}$ vertically and $\Delta x=333 \mathrm{~m}$ horizontally between -0.5 and $8.2 \mathrm{~km}$ AMSL. The CALIOP level 2 aerosol products are produced at two horizontal resolutions along the ground track: $\Delta \mathrm{x}=5$ and $40 \mathrm{~km}$, corresponding to layer products (altitude and backscatter to extinction rtio (BER)) and profile products (aerosol optical properties), respectively.

[7] For the nighttime portion of an orbit, the $532 \mathrm{~nm}$ calibration constant is determined for every $55-\mathrm{km}$ average profile (11 frames) by comparing the 532-parallel polarization signal in the $30-34 \mathrm{~km}$ altitude range to a scattering model value derived from molecular and ozone number densities provided by NASA's Global Modeling and Assimilation Office (GMAO). A constant value of the calibration constant is applied to all single-shot profiles in each $55-\mathrm{km}$ averaging region after an additional smoothing operation that is applied to the values retrieved at $55-\mathrm{km}$ intervals [Hostetler et al., 2005; Powell et al., 2009]. The calibration technique used during nighttime cannot be used in the daytime portions of the orbits, because the noise associated with solar background signals (i.e., sunlight) degrades the backscatter signal-to-noise ratio (SNR) below usable levels in the calibration region. Therefore, for the daytime portion of the orbit, the calibration constants are derived by interpolating between values derived in the adjacent nighttime portions of the orbits [Powell et al., 2008]. 


\subsection{LAUVA/EZ Lidar $^{\circledR}$ on Board ULA}

[8] The Lidar Aérosol UltraViolet Aéroporté (LAUVA) system is a homemade prototype backscatter lidar developed by the Commissariat à l'Energie Atomique (CEA) and the Centre National de la Recherche Scientifique (CNRS), emitting in the ultraviolet based on a pulsed Nd:YAG laser operating at $355 \mathrm{~nm}$. It is now commercialized by the LEOSPHERE Company under the name of EZ Lidar ${ }^{\mathbb{B}}$. It is designed to monitor the aerosol dispersion in the low and middle troposphere. It is light, compact, eye-safe and suitable for an airborne platform. The range-resolution along the line of sight is $1.5 \mathrm{~m}$. For this experiment, it was operated onboard an Ultra Light Aircraft (ULA) of the Air Création Company (http://www.aircreation.fr), which is a high performance model Tanarg 912-XS weight-shift control ULA platform. Technical features are fully described by Chazette et al. [2007]. The advantages of such an aircraft are (1) its excellent manoeuverability in small atmospheric volumes, (2) an ability to cruise at levels from near-surface up to more than $5.5 \mathrm{~km}$, and (3) a low flight speed that minimizes the isokinetic problems involved in situ aerosol sampling. Furthermore, it can use small airfields for takeoff and landing. The advantage of the EZ Lidar ${ }^{\mathbb{B}}$ in the ULA payload is to permit the retrieval of the vertical profile of the aerosol extinction coefficient $\alpha_{a}$ independently of another instrument and without having to make an assumption regarding the aerosol backscatter-to-extinction ratio $(B E R)$ value [Chazette et al., 2007]. This is a result of its ability to point horizontally during ascent and descent flight phases. Furthermore, the combination of horizontal pointing during ascent or descent with nadir shooting during transects permits the derivation of the vertical aerosol $B E R$ profiles.

[9] The ULA payload also contained a Personal DataRam (PDRam) scatterometer to measure the aerosol side scattering in the near-infrared and a Vaisala meteorological probe type PTU200 to measure the temperature, the relative humidity, and the atmospheric pressure. The PDRam is a small portable nephelometer-type instrument documented by Dulac et al. [2001]. The PDRam measures aerosol side scattering in the angular range of $45-95^{\circ}$ at a wavelength of $880 \mathrm{~nm}$, with a bandwidth of $40 \mathrm{~nm}$. The PDRam is calibrated in terms of both Mie scattering using a gaseous reference scatterer and with aerosol extinction at $870 \mathrm{~nm}$ against a ground-based Sun photometer as in work by Chazette et al. [2007].

[10] In addition, a global positioning system manufactured by Trimble SA was used to measure the location of the ULA, with accuracies of 15 and $10 \mathrm{~m}$ for vertical and horizontal positions, respectively. An electronic flight information system manufactured by Dynon Avionics SA was used to locate the lidar line of sight in the three dimensions of space with accuracy close to $0.5^{\circ}$.

\subsection{LESAA}

[11] The Lidar pour l'Etude et le Suivi de l'Aérosol Atmosphérique (LESAA) was developed by the Commissariat à l'Energie Atomique (CEA) to measure the atmospheric reflectivity at 355 or $532 \mathrm{~nm}$ in the lower troposphere over polluted areas. LESAA uses the aerosol backscattering to examine the lower troposphere structure with a vertical resolution of $7.5 \mathrm{~m}$ [Chazette et al., 2005b].
The sky background radiance is measured from the lidar signal at high altitude ( 45 to $55 \mathrm{~km}$ ) from where the laser beam contribution is considered to be negligible. The lidar measurement is associated with an overlap factor close to 1 at $\sim 200 \mathrm{~m}$ above the ground level (agl). During this experiment the wavelength of $532 \mathrm{~nm}$ was not used due to ocular safety requirements in the vicinity of a populated area and airports.

\section{Additional Data}

\subsection{MODIS}

[12] The polar orbiting Moderate Resolution Imaging Spectrometer (MODIS) is an earth-viewing sensor developed for the Earth Observing System (EOS) [Salomonson et al., 1989]. It has been launched aboard both NASA's Terra (in 1999) and Aqua (in 2002) satellite platforms. MODIS makes near-global daily observations of the Earth in 36 spectral bands ranging from 0.4 to $14.3 \mu \mathrm{m}$. These measurements are used to derive the spectral aerosol optical thickness (AOT) over the oceans globally and over a portion of the continents. The MODIS aerosol (level-2) product contains data having a spatial resolution (pixel size) of $10 \mathrm{~km} \times 10 \mathrm{~km}$ at nadir (http://modis-atmos.gsfc.nasa.gov/ MOD04_L2/index.html). Remer et al. [2005] confirm that the 1-sigma of MODIS optical thickness retrievals fall within the predicted uncertainty of $\Delta \tau= \pm 0.05 \cdot \tau \pm 0.03$ over ocean and $\Delta \tau= \pm 0.15 \cdot \tau \pm 0.05$ over land.

\subsection{SEVIRI}

[13] The horizontal structure of aerosol plumes is qualitatively described using observations from the Spinning Enhanced Visible and Infra Red Imager (SEVIRI) onboard Meteosat Second Generation (MSG) (see http://www-icare. univ-lille1.fr/). In comparison with the first generation Meteosat platform, MSG has a better spatial resolution, $3 \mathrm{~km}$ sampling distance and $1 \mathrm{~km}$ for the High Resolution Visible (HRV) channel, a better spectral resolution (12 channels ranging from the visible to the infrared), a shorter repeat cycle of $15 \mathrm{mn}$, a better radiometric performance and improved data encoding facilities. The retrieval of the AOT at $550 \mathrm{~nm}$ for clear air pixels over the ocean surface is based on a look-up table algorithm that has been validated by comparison of resulting AOTs to direct measurements by Sun photometers performed in the tropical Atlantic Ocean and the western Mediterranean [Thieuleux et al., 2005].

\subsection{Sun Photometer}

[14] We operated a CIMEL ${ }^{\circledR}$ Sun photometer instrument that performs integrated measurements of solar light absorption, in order to retrieve the aerosol optical thickness (AOT) at several wavelengths and the Angström exponent. The channels used for this study are centered at 340, 380, 440, 500,674 and $870 \mathrm{~nm}$, with bandwidths lower than $20 \mathrm{~nm}$. The instrument field of view is about $1^{\circ}$ [e.g., Holben et al., 1998]. Optical thickness data were obtained after inversion with the procedure used in the AErosol RObotic NETwork (AERONET). The AERONET database gives a maximal absolute uncertainty of 0.02 for the optical thickness, which is wavelength dependent, due to calibration uncertainty for the field instruments. The uncertainty in the Angström 
exponent has been shown to be $\sim 0.03$ for an AOT of $\sim 0.2$ [Hamonou et al., 1999].

\subsection{Meteorological Fields}

[15] The meteorological fields are extracted at a time step of $6 \mathrm{~h}$ from the output of the operational model of the European Center for Medium Range Weather Forecast (ECMWF; http:// www.ecmwf.int/products/data/operational_system) which has 21 vertical sigma-levels. They are interpolated on a regular latitude-longitude grid with a horizontal resolution of $0.5^{\circ}$.

\section{Experimental Plan and Methodology}

[16] The question arises as to whether the instrument CALIOP has the capability to identify the low and moderate aerosol load particularly above a complex topography. This leads to limited number of lidar profiles available to calculate a mean CALIOP profile over a given valley and thus yields a low signal-to-noise ratio inside the PBL (SNR 7). Such a situation is often met above France and other continental areas of the Earth. Hence, the experiment took place from 20 June to 10 July, 2007, in the region between the Cévennes mountains and the Gulf of Lion in the south of France in the northwestern Mediterranean Sea (Figure 1).

[17] Five occurrences with the CALIPSO platform have been covered. Unfortunately, the period was not optimal because numerous thunderstorms occurred. There were periods where rain persisted after the storms. Due to these meteorological constraints, only 3 overflights were relevant where both ground and airborne lidar measurements could be compared to the CALIOP vertical profiles: 23 and 30 June, 2007 during daytime and July 7, 2007 during nighttime. Ground and airborne measurements are performed during $\pm 20 \mathrm{~min}$ around the overflights of CALIPSO.

[18] The comparison between CALIOP and our lidars is carried out in terms of the aerosol extinction coefficient $\left(\alpha_{a}\right)$ derived from both the operational algorithm (CALIOP level-2 data) and a classical inversion scheme that we applied to the CALIOP level-1 data.

\subsection{Generalities on the Lidar Equation and Its Uncertainty Sources}

[19] The lidar equation gives the range-corrected signal $S(r)$ for the emitted wavelength as a function of the range $r$ along the line of sight, the total backscatter $\beta(r)$ and extinction coefficients $\alpha(r)$ [Measures, 1984] as follows:

$$
S(r)=C \cdot \beta(r) \cdot \exp \left[-2 \cdot \int_{0}^{r} \alpha\left(r^{\prime}\right) \cdot d r^{\prime}\right]
$$

where $\mathrm{C}$ is a calibration constant which characterizes the overall optical and electrical efficiency of the lidar system. The extinction and backscatter coefficients represent the sum of contributions of both Rayleigh scattering by molecules $\left(\alpha_{m}(r)\right.$ and $\left.\beta_{m}(r)\right)$ and extinction by aerosol particles $\left(\alpha_{a}(r)\right.$ and $\left.\beta_{a}(r)\right)$ :

$$
\begin{aligned}
& \alpha(r)=\alpha_{m}(r)+\alpha_{\mathrm{a}}(r) \\
& \beta(r)=\beta_{\mathrm{m}}(r)+\beta_{\mathrm{a}}(r)
\end{aligned}
$$

The determination of $\beta(r)$ from (1) requires the quantitative knowledge of the extinction coefficient $\alpha(r)$. The system to be solved is thus underdetermined, and a second relationship is needed to link together $\alpha(r)$ and $\beta(r)$. If the value of the backscatter phase function is assumed to be known, the following relations can be added:

$$
\begin{gathered}
B E R(r)=\frac{\beta_{a}(r)}{\alpha_{a}(r)} \\
\varphi_{m}=\frac{\beta_{m}(r)}{\alpha_{m}(r)}
\end{gathered}
$$

where $\varphi_{m}$ is the Rayleigh backscatter phase function normalized for molecular scattering $\left(\varphi_{m} \sim 3 / 8 \pi\right)$ [Nicolet, 1984; Bucholtz, 1995], and BER(r) is the aerosol backscatter-toextinction ratio or particle backscatter phase function, which depends on the size distribution and refractive index of the aerosols and can thus vary with altitude (BER is the inverse of the so-called lidar ratio). It is then equivalent to solve the lidar equation (1) in terms of $\alpha_{a}$ or $\beta_{a}$. In this paper we choose to work in considering $\alpha_{a}$ because this is the more relevant geophysical parameter for air quality applications [e.g., Raut and Chazette, 2009] and for climate studies [e.g., Raut and Chazette, 2008b].

[20] $S(r)$ is corrected from the background sky radiance which is simultaneously measured with the lidar profile. Klett [1985] gives the solution to the inverse problem, which is the solution of a Bernoulli first order differential equation:

$$
\beta(r)=\frac{S(r) \cdot Q(r)}{\frac{S_{0}}{\beta_{0}}+2 \int_{r}^{r_{0}} \frac{1}{B E R\left(r^{\prime}\right)} S\left(r^{\prime}\right) \cdot Q\left(r^{\prime}\right) \cdot d r^{\prime}}
$$

where $S_{0}$ and $\beta_{0}$ are respectively the signal and the backscatter coefficient at a reference distance $r_{0}$ along the line of sight. $Q(r)$ is the correction related to the differential molecular optical thickness calculated from the vertical profile of the molecular scattering coefficient $\alpha_{m}(z)$ :

$$
Q(r)=\exp \left(2 \cdot r \int_{r}^{r_{0}}\left[\frac{3}{8 \pi \cdot B E R\left(r^{\prime}\right)}-1\right] \cdot \alpha_{m}\left(r^{\prime}\right) \cdot d r^{\prime}\right)
$$

[21] The lidar-derived AOT $\left(\tau_{a}\right)$ is calculated at the altitude $z$ as the integral of the extinction coefficient from the ground surface up to the reference $r_{0}$ taking into account of the pointing angle $\theta(z=r \cdot \cos (\theta))$ and the altitude of the ground level $z_{g}$ :

$$
\tau_{a}(z)=\int_{z_{g}}^{z} \alpha_{a}\left(z^{\prime}\right) d z^{\prime}
$$

[22] The different sources of uncertainty on the lidarderived $\alpha_{a}$ are well described in Chazette et al. [1995]. Uncertainties in the determination of $\alpha_{a}$ can be related to five main causes: (1) the statistical fluctuations of the measured signal, associated with random detection processes, (2) the uncertainty on the lidar signal in the altitude 


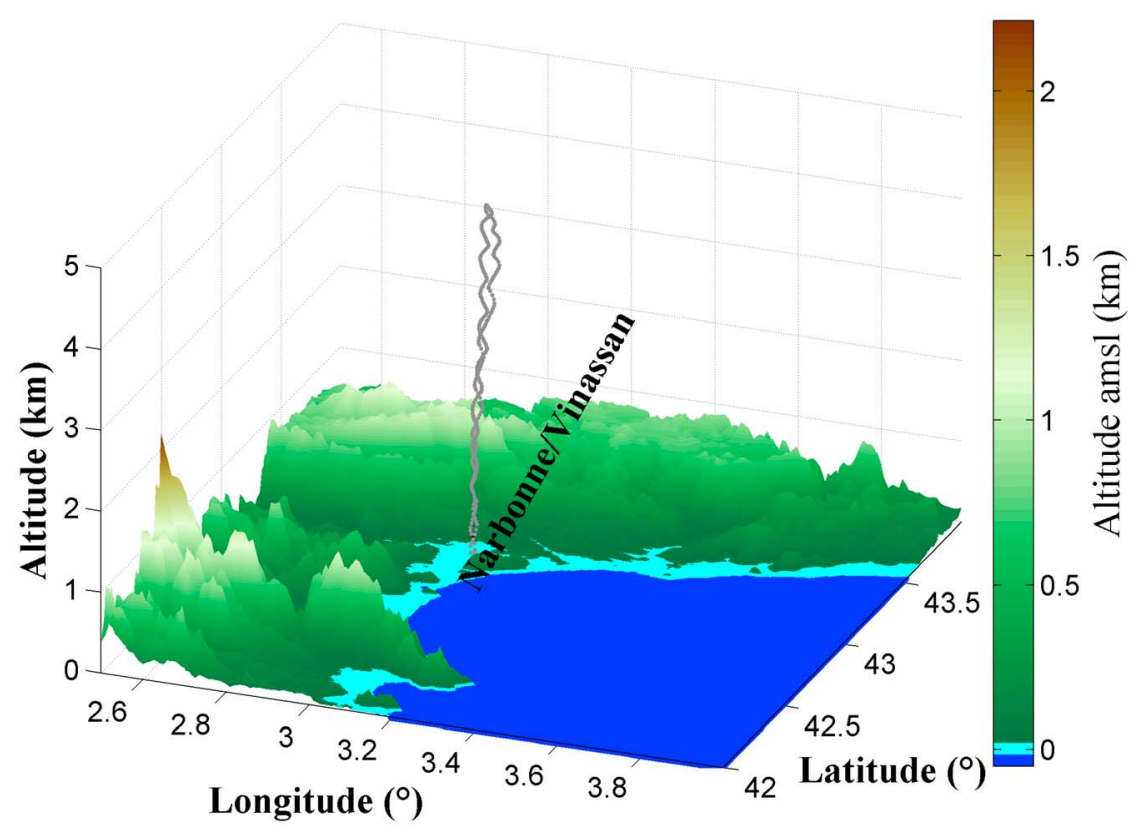

Figure 2. A typical ULA flight plan performed during the experiment, on 30 June 2007. On this date, the location is close to the city of Narbonne and the ULA took off from Narbonne-Vinassan airfield.

range used for the normalization, (3) the uncertainty on the a priori knowledge of the vertical profile of the Rayleigh backscatter coefficient as determined from ancillary measurements, (4) the uncertainty on $B E R$ and on its altitude dependence, and (5) the overall uncertainty resulting from the value of the necessary exogenous constraint (i.e., the total optical thickness). These different sources of uncertainties will be discussed hereafter for each lidar system.

\subsection{Airborne Lidar Measurements}

[23] Airborne lidar measurements have been used here as in work by Chazette et al. [2007] to assess the vertical profile of both the aerosol extinction coefficient and $B E R$. Such an approach supposed that the atmospheric column did not change during the ascent or descent in terms of aerosol content. The time between the take-off and the top altitude reached by the ULA $(\sim 4 \mathrm{~km})$ was of the order of $20 \mathrm{~min}$. The previous assumption is therefore reasonable.

[24] For the whole set of measurements obtained from the ULA, the flight plans were defined for vertical exploration of the low troposphere between the ground level and a maximum of $5 \mathrm{~km}$ AMSL. The ULA described spirals during both the ascent and the descent as illustrated on Figure 2. During both the ascent and the descent, the lidar was pointing horizontally to retrieve the vertical profile of the aerosol extinction coefficient $\alpha_{a 355}$ at the wavelength of $355 \mathrm{~nm}$ and altitude $z$ following equation (9) as defined by Chazette et al. [2007]:

$$
\alpha_{a 355}(z)=-\frac{1}{2} \frac{\partial \operatorname{Ln}(S(r, z))}{\partial r}-\alpha_{m 355}(z)
$$

This equation is directly derived from the logarithm of equation (1) under the hypothesis that the atmosphere is horizontally homogeneous from the lidar emitter to a distance $r_{M}$ from the emitter. Here the distance $r_{M}$ has been chosen equal to $1 \mathrm{~km}$. The horizontal homogeneity could be verified considering the linear character of the logarithm of $S$ against the distance.

[25] The main uncertainties in $\alpha_{a 355}$ are due to i) the detection noise, expressed in terms of signal-to-noise ratio (SNR), ii) the assessment of the molecular contribution and iii) the uncertainty on the pointing angle associated to the ULA attitude $\left(\sim 3.5^{\circ}\right)$. SNR on horizontal shooting was between 25 and 35 between 0.2 and $1 \mathrm{~km}$ from the emitter. The slope retrieval of the extinction coefficient is made within an uncertainty of $\sim 0.005 \mathrm{~km}^{-1}$. The molecular contribution is calculated using in situ measurements of both temperature and pressure and leads to a small uncertainty lower than $2 \%$ on $\alpha_{m 355}$. The influence of the variability of the pointing angle has been calculated using a Monte Carlo approach and found to be lower than $0.002 \mathrm{~km}^{-1}$. Hence, considering all the error sources to be independent, the total relative uncertainty on $\alpha_{a 355}$ is $\sim 0.007 \mathrm{~km}^{-1}$.

[26] For the duration of the high altitude leg (between 3.5 and $4 \mathrm{~km} \mathrm{AMSL}$ ), the lidar pointed at nadir to permit the assessment of the $B E R$. Instead of deriving the profile of aerosol backscatter coefficient and then producing a $B E R$ as in work by Chazette et al. [2007], we have used in this study a method based on the adjustment of a direct calculation of the lidar profile on the range corrected lidar measurement by fitting the BER using a least-mean squares adjustment on equations (1) and (4). We first located the aerosol layers and inverted the profile for the upper layer searching the BER value that minimizes the quadratic deviation between the aerosol extinction coefficient retrieved from both the horizontal shooting and the Klett's algorithm. Knowing the BER in the upper layer, we applied the same process to retrieve the BER value in the lower layer. This second step does not alter the BER found in the upper layer. This method leads to a smoother $B E R$ profile, determined within an uncertainty of $0.002 \mathrm{sr}^{-1}$. 
(a)

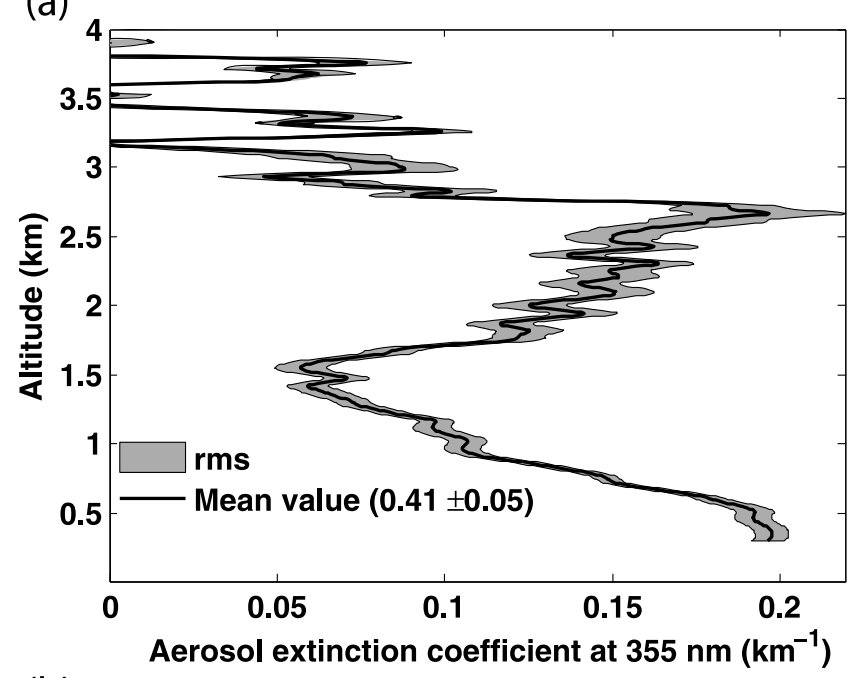

(b)

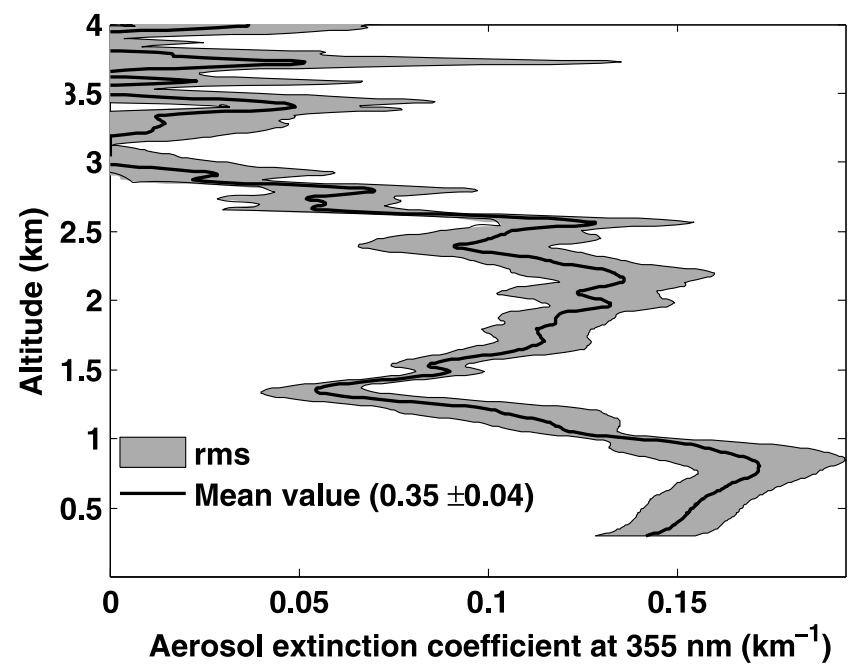

Figure 3. Vertical profiles of the aerosol extinction coefficients at $355 \mathrm{~nm}$ retrieved from the ground-based lidar LESAA at (a) 09:00 and (b) 11:00 GMT. The measurements were performed over the Narbonne airfield on 30 June 2007. The gray area represents the temporal variability of profiles during \pm 10 min around 09:00 and 11:00 GMT. The aerosol optical thickness is given in parentheses with its temporal variability. It has been calculated on the entire profile shown (from 0.25 to $4 \mathrm{~km} \mathrm{AMSL}$ ).

\subsection{CALIOP and Ground-Based Lidar}

[27] The lidar equation is under-constrained since it has 2 unknowns: the aerosol extinction coefficient and the $B E R$. The determination of $B E R$ needs considering an external constraint. To achieve this purpose, the Sun photometer measurements were used to constrain both CALIOP and the ground-based lidar inversion [Chazette, 2003]. Given adequate SNR $>10$, the mean relative error for the extinction coefficient is generally less than $10 \%$ when the lidar profiles inversion is constrained using a Sun photometer [Chazette, 2003] and when the relative humidity stays lower than $75 \%$, as it was the case here. The lidar systems overlap function is a major source of uncertainty when measuring aerosols from the ground level at low altitudes. The lidar systems used here have a complete overlap at $\sim 150$ and $\sim 200 \mathrm{~m}$ from the laser emission for LAUVA and LESAA, respectively.

[28] The molecular contribution has been calculated using meteorological parameters from ULA for ground-based lidar or using modeling outputs for CALIOP (those meteorological data are included in CALIOP level-2 data). As previously described, the associated relative uncertainty in $\alpha_{m}$ is lower than $2 \%$. Moreover, a reference value must be determined by considering the lidar signal where the molecular scattering is the major contributor to the total extinction. In this experiment, the molecular-only contribution is reached between 3 and $4.5 \mathrm{~km}$ AMSL. Cloud and aerosol contributions could appear above and below this altitude, respectively. The error due to the assumption of aerosol-free atmosphere is generally difficult to assess. Nevertheless, thanks to the horizontal lidar measurements, it was easier to define a molecular interval on the vertical profile. An uncertainty of $5 \%$ on the molecular region induces an underestimation of $\sim 1-2 \%$ within the PBL on the aerosol extinction coefficient. We have inverted CALIOP and zenith-pointing lidar profiles with the algorithm proposed by Klett [1981]. As noted by Klett [1981, 1985], major differences exist in the solution stability between down- and up-looking lidar systems. Such differences were also reported by Ansmann [2006] regarding spaceborne lidar measurements, who has shown a relative variation as large as $20 \%$ between optical aerosol properties retrieved from ground and spaceborne lidar measurements. Indeed, the inversion of spaceborne (or airborne) lidar measurement becomes more unstable when the position of the reference altitude is located above the scattering layers. It is worth noting that a stable solution can also converge toward an erroneous result [Young and Vaughan, 2009]. Moreover, an unstable solution can help determining a range for the $B E R$.

[29] Spaceborne lidar measurements are also affected by multiple-scattering [Spinhirne, 1982; Winker, 2003; Berthier et al., 2006]. In the situations encountered during the experiment the AOT $\left(\tau_{a}\right)$ was relatively low and reached a maximum value of $\sim 0.25$ at $532 \mathrm{~nm}$. Such a value leads to a BER overestimation due to a multiple scattering effect lower than $4 \%$, as computed from [Berthier et al., 2006]. The relative error in BER is expressed against the single $(S)$ and multiple scattering $\left(S_{m u l}\right)$ contributions:

$$
\frac{\Delta B E R(z)}{B E R(z)}=\frac{\ln \left(\frac{S(z)}{S(z)-S_{m u l}(z)}\right)}{2 \cdot\left(\tau_{a}(z=0)-\tau_{a}(z)\right)}
$$

The statistical fluctuations of the lidar signal due to the detection and expressed in terms of SNR is a function of the number of profiles used for averaging but also of the daytime and nighttime conditions. It also influences the reference value used to normalize the lidar profile in the molecular region. SNR values are assessed in each case considered and the corresponding uncertainty on $\alpha_{a}$ is provided hereafter.

\section{Observation of a Pollution Event}

[30] The most interesting aerosol event occurred on the 30 June, 2007 above Narbonne $\left(43^{\circ} 11^{\prime} \mathrm{N}, 3^{\circ} 03^{\prime} \mathrm{E}\right)$ (Figure 2). As revealed from ground-based lidar profiling in the 


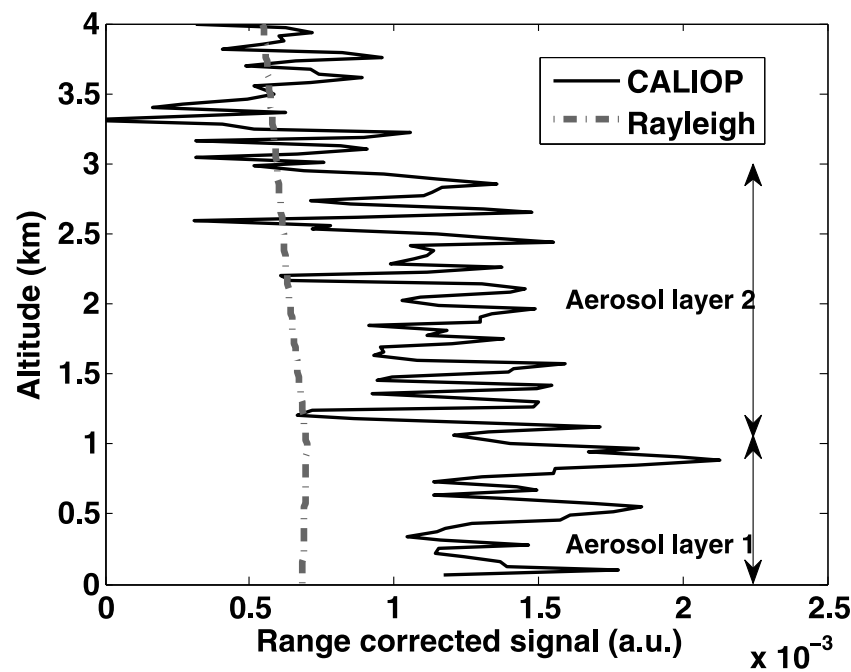

Figure 4. The mean CALIOP range-corrected signal above the Narbonne area, on 30 June 2007 at 12:55 GMT. The gray dash-dotted line corresponds to the molecular (Rayleigh) signal if no aerosol were present.

morning, clouds were present in the middle troposphere. Fortunately, the atmosphere was clear between the top of the aerosol layer and the cloud base. Results for the aerosol extinction coefficient are given in Figure 3 for ground-based lidar measurements performed at 09:00 and 11:00 GMT. Two aerosol layers are clearly visible. The lowest one corresponds to the PBL that grows from 400 to $500 \mathrm{~m}$ to $900 \mathrm{~m}$ between 09:00 (Figure 3a) and 11:00 (Figure 3b) GMT. The second aerosol layer is located between $\sim 1.5$ and $2.5-3 \mathrm{~km}$ AMSL.

\subsection{Synergy Between CALIOP and the Sun Photometer}

[31] Here we derive the $B E R$ by inverting CALIOP level-1 data using the Sun photometer-derived aerosol optical depth as a constraint. Figure 4 gives the mean range-corrected signal from the CALIOP instrument level-1 data during the overflight of the CALIPSO satellite at 13:01 GMT. On individual profiles, no coherent aerosol structure can be identified from the noise. However, by averaging the 134 profiles shown in Figure 4, it becomes possible to distinguish an aerosol signature from the surface up to about $3 \mathrm{~km}$ AMSL in addition to the molecular contribution (Rayleigh scattering) on the effective signal. Two aerosol layers seem to appear between 0 and $1 \mathrm{~km}$ AMSL and 1 and $3 \mathrm{~km}$ AMSL, respectively. As no cloud was present at the time of the CALIPSO overflight, the Sun photometer can be used to constrain the inversion of the mean CALIOP vertical profile in terms of aerosol extinction coefficient. The result is shown in Figure 5a. We filtered the mean range-corrected CALIOP profile using a low-pass frequency filter. The SNR within the PBL is close to 13 and the vertical resolution is $\sim 100 \mathrm{~m}$. The synergy between CALIOP and the groundbased Sun photometer leads to an apparent $B E R$ of $\sim 0.026 \pm$ $0.002 \mathrm{sr}^{-1}$ very close to the actual $B E R$ because the multiple scattering effect is low at the level of AOT encountered $\left(\tau_{a 532} \sim 0.22 \pm 0.02\right)$.

\subsection{Robustness of the Synergy Between Lidars and the Sun Photometer}

[32] In order to check the result from the synergy between CALIOP and the Sun photometer, a similar inversion approach has been used for the ground-based zenith pointing lidar LESAA. Such a coupling leads to a BER of $\sim 0.020 \pm$ $0.003 \mathrm{sr}^{-1}$ for $\tau_{a 355} \sim 0.32 \pm 0.05$ and the aerosol extinction profile at $355 \mathrm{~nm}$ is given in Figure $5 \mathrm{~b}$. As a consequence, the $B E R$ is found smaller at $355 \mathrm{~nm}\left(0.020 \mathrm{sr}^{-1}\right)$ than at $532 \mathrm{~nm}\left(0.026 \mathrm{sr}^{-1}\right)$. Such a result is expected for submicron size particles and has already been found for urban aerosols
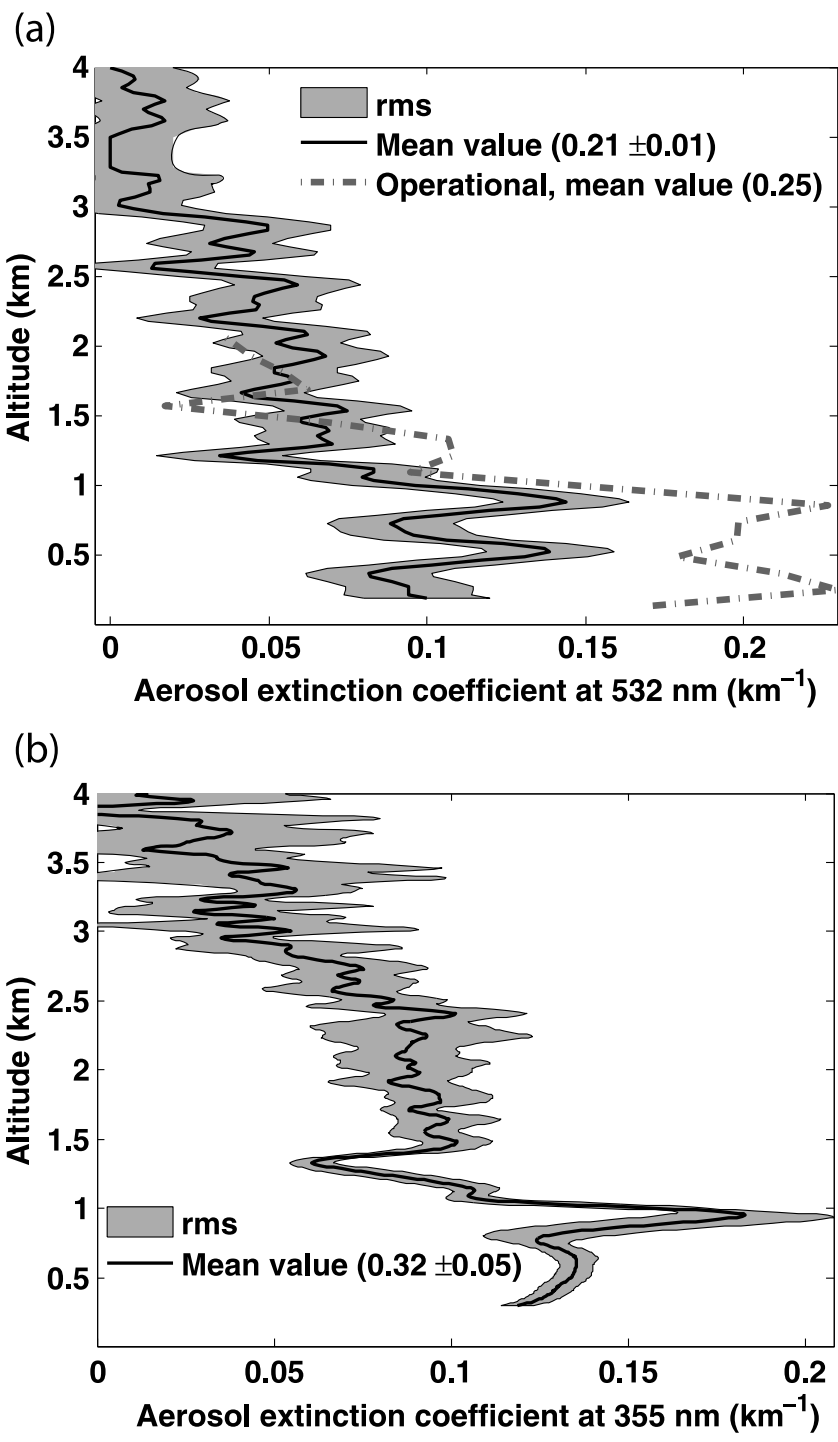

Figure 5. The aerosol vertical extinction coefficient retrieved from (a) CALIOP and (b) LESAA lidar systems on 30 June 2007, 12:55 GMT. The gray area in Figure 5a represents the error on the CALIOP-derived profile, while the dashed line corresponds to the result from the operational algorithm. The gray area in Figure $5 \mathrm{~b}$ represents the temporal variability within $\pm 20 \mathrm{~min}$ around the CALIPSO overflight. The aerosol optical thickness is given in parentheses with its temporal variability. For the operational product, the aerosol optical thickness is calculated using available points. 
Table 1. Characteristics of the Aerosol Layers Detected Above Narbonne on 30 June $2007^{\mathrm{a}}$

\begin{tabular}{|c|c|c|c|c|c|}
\hline & $\begin{array}{l}\text { Top Altitude First } \\
\text { Layer PBL (km) }\end{array}$ & $\begin{array}{c}\text { Top Altitude } \\
\text { Second Layer } \\
\text { Upper Layer }(\mathrm{km})\end{array}$ & $\tau_{a}$ & $a$ & $B E R\left(\mathrm{sr}^{-1}\right)$ \\
\hline \multicolumn{6}{|l|}{ CALIOP } \\
\hline $\begin{array}{c}\text { Operational } \\
\text { products } \\
532 \mathrm{~nm} \\
1064 \mathrm{~nm}\end{array}$ & $\begin{array}{c}0.9 \\
\Delta x=5 \mathrm{~km}\end{array}$ & Not detected & $\begin{array}{c}0.25 \\
0.072 \\
\Delta x=40 \mathrm{~km}\end{array}$ & $1.77 \pm 0.4$ & $\begin{array}{c}\text { PBL } \\
\text { 0.015-0.050 } \\
\text { Upper layer } \\
0.025 \\
\Delta x=40 \mathrm{~km}\end{array}$ \\
\hline $\begin{array}{r}\text { This work } \\
532 \mathrm{~nm}\end{array}$ & $\begin{array}{c}0.9 \mathrm{~km} \\
\Delta x \sim 45 \mathrm{~km}\end{array}$ & $\begin{array}{c}3 \mathrm{~km} \\
\Delta x \sim 45 \mathrm{~km}\end{array}$ & $\begin{array}{c}0.22 \\
\Delta x \sim 45 \mathrm{~km}\end{array}$ & - & $\begin{array}{c}0.026 \pm \\
0.002 \\
\Delta x \sim 45 \mathrm{~km}\end{array}$ \\
\hline LESAA $(355 \mathrm{~nm})$ & $0.9 \pm 0.03$ & $2.8 \pm 0.03$ & $0.32 \pm 0.05$ & $0.93 \pm 0.3$ & $0.020 \pm 0.003$ \\
\hline $\begin{array}{l}\text { ULA/EZ Lidar } \\
\quad(355 \mathrm{~nm})\end{array}$ & $0.9 \pm 0.05$ & $2.8 \pm 0.05$ & $0.27 \pm 0.01$ & $0.51 \pm 0.3$ & $\begin{array}{c}\text { PBL } \\
0.020 \pm 0.003 \\
\text { Upper layer } \\
0.015 \pm 0.003\end{array}$ \\
\hline PDRam $(880 \mathrm{~nm})$ & $0.9 \pm 0.05$ & $2.7 \pm 0.05$ & $0.10 \pm 0.01$ & $1.8 \pm 0.3$ & \\
\hline MODIS $(550 \mathrm{~nm})$ & & & $0.25 \pm 0.12$ & $1.2 \pm 0.6$ & \\
\hline SEVERI $(550 \mathrm{~nm})$ & & & $0.24 \pm 0.05$ & $0.70 \pm 0.3$ & \\
\hline Sun photometer $380 \mathrm{~nm}$ & & & $0.34 \pm 0.02$ & $0.97 \pm 0.2$ & \\
\hline $500 \mathrm{~nm}$ & & & $0.23 \pm 0.02$ & - & \\
\hline $870 \mathrm{~nm}$ & & & $0.10 \pm 0.02$ & $1.65 \pm 0.3$ & \\
\hline $1020 \mathrm{~nm}$ & & & $0.07 \pm 0.02$ & $1.72 \pm 0.3$ & \\
\hline$\theta_{\mathrm{w}} \& \mathrm{RH}$ & 0.9 & 2.9 & & & \\
\hline
\end{tabular}

${ }^{\mathrm{a}}$ The Angström exponents $a$ have been calculated for LESAA, ULA and PDRam against the aerosol optical thickness at $532 \mathrm{~nm}$ retrieved from this work. The values retrieved from the operational CALIOP algorithms are given in bold. In the first column are indicated both instrument and wavelength used. The \pm ranges include both the temporal variability during the satellite overpass and the uncertainties on the retrieved aerosol optical parameters. $\Delta x$ represents the ground track interval over which profiles are averaged.

in Paris area $\left(0.014\right.$ and $0.011 \mathrm{sr}^{-1}$ at 532 and $355 \mathrm{~nm}$, respectively [Raut and Chazette, 2008a]. Direct AOT comparisons have not been performed since the wavelengths are different. Nevertheless, the resulting Angström exponent is consistent with those derived from the Sun photometer (Table 1).

[33] Figure 6a gives the vertical profile of $\alpha_{a 355}$ independently inferred from the horizontal shooting with the airborne lidar. This approach leads to a slightly smaller aerosol optical depth $\tau_{a 355}$ of $0.27 \pm 0.01$ than LESAA $(0.32 \pm 0.05)$ but both values remain within the limits of the error bars. Hence, we can conclude that our BER assessment from the coupling of the ground-based lidar and Sun photometer can be considered as reasonable. In Figure $6 \mathrm{~b}$, the aerosol extinction at $880 \mathrm{~nm}$ derived from the PDRam is also given and results in $\tau_{a 880} \approx 0.10 \pm 0.01$, which is in agreement with the Sun photometer measurements (Table 1).

[34] The coupling between horizontal and nadir lidar shooting modes from the ULA offers the opportunity to determine by an independent way the vertical profile of BER at $355 \mathrm{~nm}$ and to subsequently explore whether the 2 aerosol layers are of comparable nature and close to the value retrieved from the synergy between ground-based lidar and Sun photometer. The BER profile was assessed as explained in section 4.2 (Figure 7a) and leads to the calculated range corrected lidar signal given in Figure $7 \mathrm{~b}$. We computed the range-corrected lidar profile using both the aerosol extinction coefficient retrieved from horizontal shooting and the previous BER (Figure 7b) and it matches well the lidar nadir measurements. This confirms the extinction and BER values previously determined. We retrieved significantly different BER values at $355 \mathrm{~nm}$ in the two layers: $0.020 \pm 0.003 \mathrm{sr}^{-1}$ in the lower layer and $0.015 \pm$ $0.003 \mathrm{sr}^{-1}$ in the upper layer. These values are in good agreement with the column-averaged BER $\left(0.020 \pm 0.003 \mathrm{sr}^{-1}\right)$ retrieved from the synergy between LESAA and the sunphotometer. It is a good indicator that the column-integrated BER at $532 \mathrm{~nm}\left(\sim 0.026 \pm 0.002 \mathrm{sr}^{-1}\right)$ derived from the synergy between CALIOP and the Sun photometer is close to the true value.

[35] Table 1 reports the vertical structure of scattering layers from our different retrievals (CALIOP+Sun photometer, LESAA+Sun photometer, ULA, PDRam). Results are very similar and indicate two aerosol layers with small differences in top altitude of the upper layer (Table 1). Moreover, meteorological parameters as potential temperature $\left(\theta_{w}\right)$ and relative humidity $(R H)$ highlight the same vertical structures (Figure 8). The marked difference in $R H$ between the planetary boundary layer (PBL) and the layer above may indicate that these 2 layers are from different origins and thus likely associated to different $B E R$ values.

\subsection{Comparison to the Aerosol Optical Properties Derived From CALIOP Operational Products}

\subsubsection{Aerosol Extinction Coefficient}

[36] Now we compare our CALIOP-derived aerosol extinction coefficient vertical profile with the profile from the operational algorithm (level-2 data), also shown in Figure 5a with a vertical resolution of $120 \mathrm{~m}$. The agreement appears reasonable within the upper layer. Nevertheless, a significant discrepancy appears in the PBL with an overestimation of the operational algorithm-derived $\alpha_{\mathrm{a}}$ in comparison to that derived from the inversion we performed using the synergy between CALIOP and the Sun photometer. 
(a)

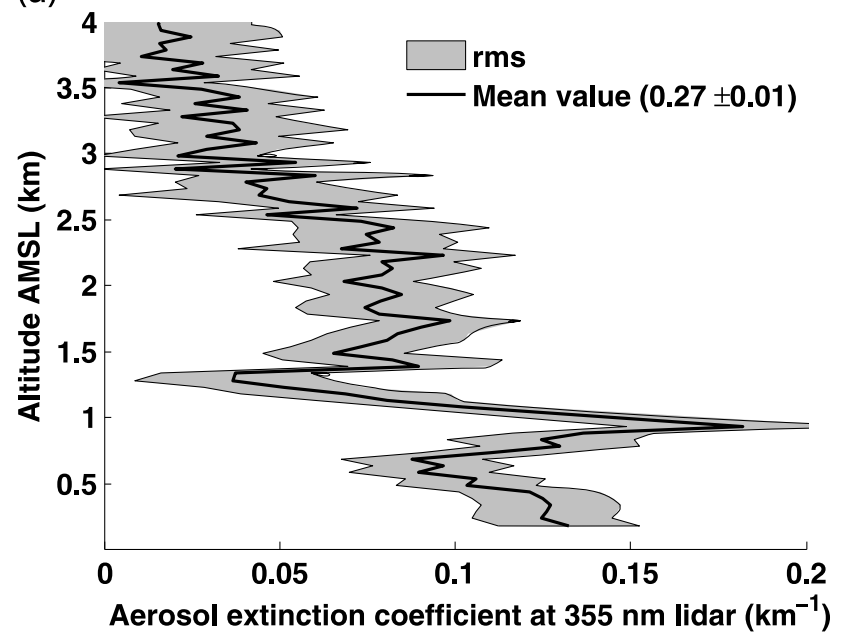

(b)

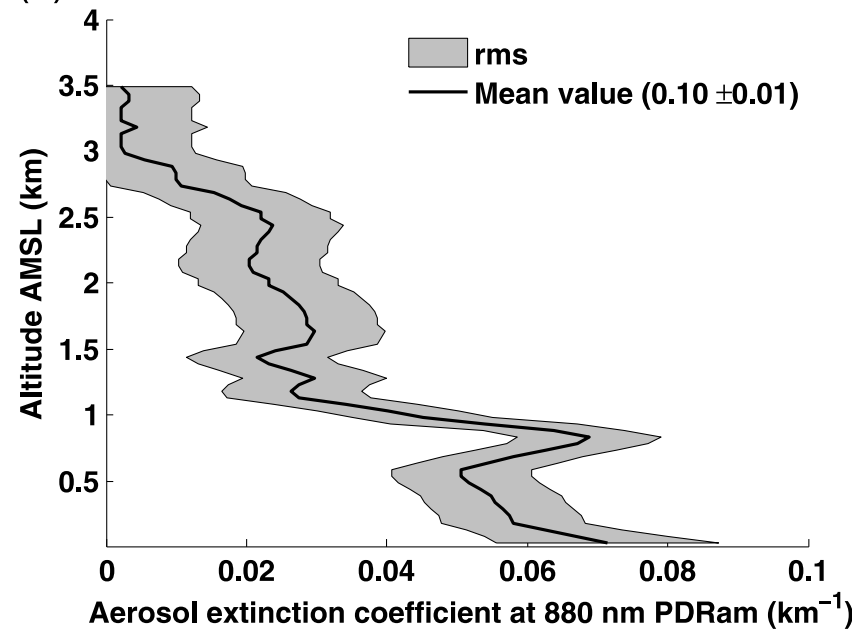

Figure 6. Vertical profiles of the aerosol extinction coefficient retrieved from (a) horizontal lidar shooting and (b) PDRam in situ instrument aboard the ULA on 30 June 2007 during ascent or descent. The gray area represents the error around the mean value. The aerosol optical thickness is given in parentheses with its uncertainty.

Such a discrepancy could be due to the BER selection by the operational algorithm for a pre-defined aerosol type, which is made difficult because of the weak SNR.

\subsubsection{Aerosol Backscatter to Extinction Ratio}

[37] Here we compare our $B E R$ retrievals with the vertical profile of $B E R$ at $532 \mathrm{~nm}$ extracted from the CALIOP operational level-2 product. It has been done by dividing the extracted profiles of aerosol backscatter and extinction coefficients available at $40 \mathrm{~km}$ horizontal resolution. Despite the wavelength difference, the result provided in Figure $7 \mathrm{a}$ is similar to our retrieval from the ULA lidar at $355 \mathrm{~nm}$ in the PBL. Normally, BER at $532 \mathrm{~nm}$ is larger than at $355 \mathrm{~nm}$ except in the presence of coarse aerosols. The value above $1.5 \mathrm{~km}$ is different but more than one could expect $\left(0.025 \mathrm{sr}^{-1}\right.$ at $532 \mathrm{~nm}$ instead of $0.015 \mathrm{sr}^{-1}$ at $\left.355 \mathrm{~nm}\right)$.

[38] In fact, the $40-\mathrm{km}$ mean BER profile is produced from operational samples at the horizontal resolution of $5 \mathrm{~km}$ based on the look-up table described by Omar et al.
[2009]. The operational algorithm of CALIOP uses the integrated attenuated backscatter and volume depolarization ratio to assign BER values to the detected layers [e.g., Liu et al., 2005; Omar et al., 2009]. Only 9 of such samples obtained above the Mediterranean Sea close to the sea coast are available and none over land. In the upper layer, the $B E R$ is the same in each sample and equals to $0.025 \mathrm{sr}^{-1}$, a value corresponding to the desert dust aerosol model used in the operational algorithm. This is further discussed in section 5.5. A variability appears for the lower layer where $B E R$ varies from 0.015 (polluted dust) to $0.050 \mathrm{sr}^{-1}$ (marine aerosols) between the 9 CALIOP samples. Our results are included into this broad range. As shown in Figure $7 \mathrm{a}$, a third intermediate layer is even identified between 1.2 and

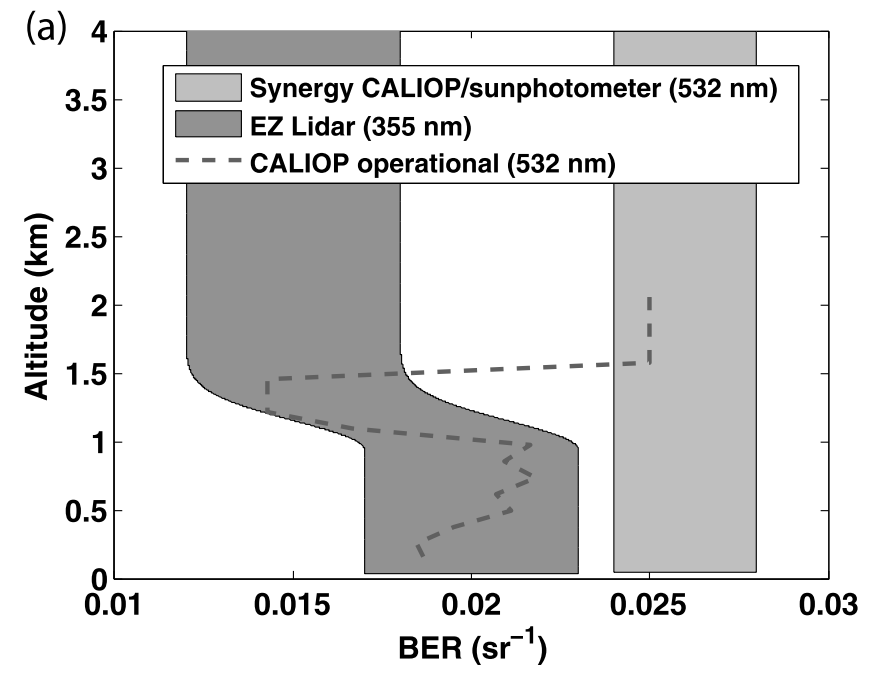

(b)

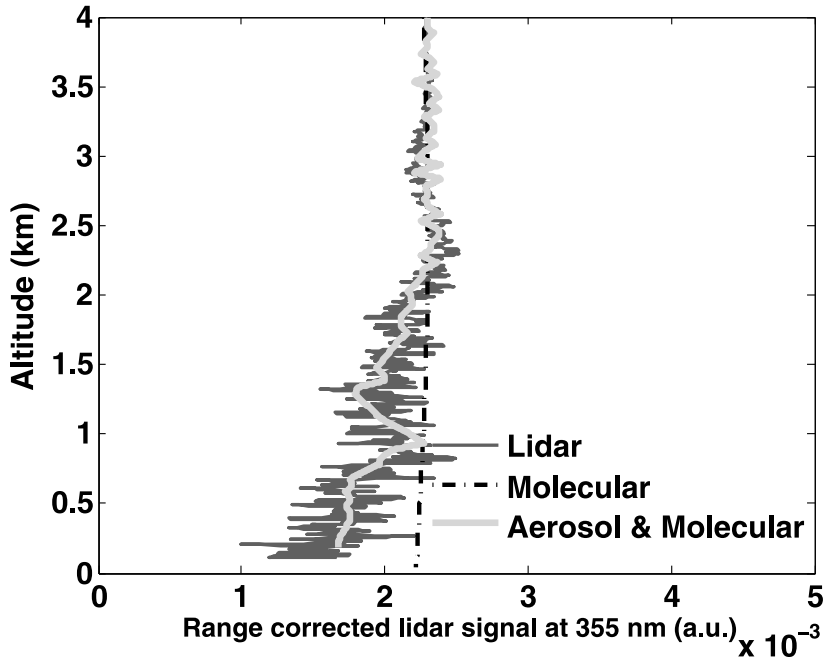

Figure 7. (a) Vertical profiles of $B E R$ retrieved on the 30 June, 2007 from (1) the synergy between CALIOP and the Sun photometer, (2) the nadir shooting mode of the lidar aboard the ULA (at $355 \mathrm{~nm}$ ), and (3) the profile derived from the operational algorithm of the CALIOP instrument $(532 \mathrm{~nm})$. The gray areas represent the possible values of BER. (b) The coherence between the average nadir lidar profiles calculated and measured from the ULA, where the black dash-dotted line gives the contribution of the molecular scattering alone. 


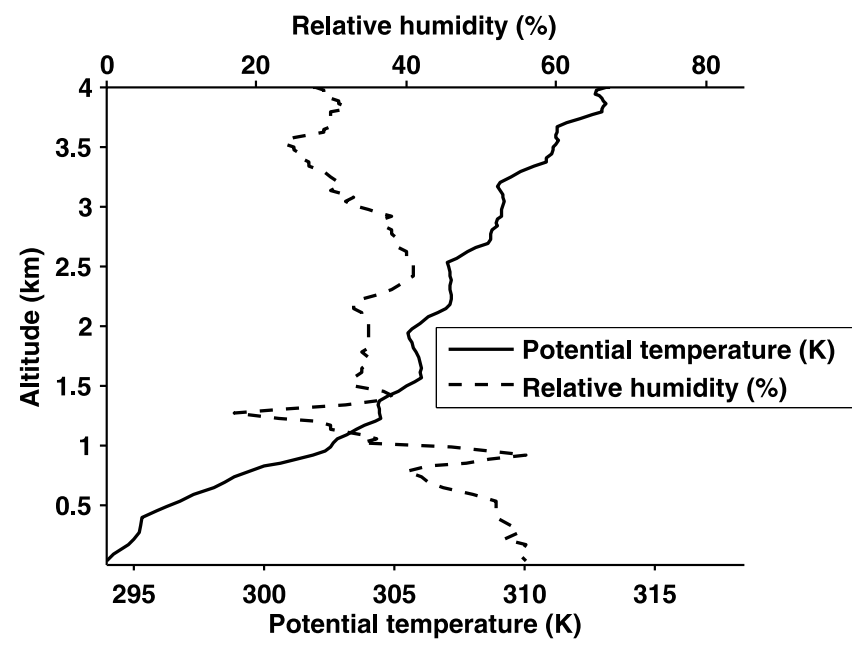

Figure 8. Vertical profiles of potential temperature and relative humidity acquired simultaneously to the lidar horizontal shooting aboard the ULA on 30 June 2007 ( 12:55 GMT).

$1.5 \mathrm{~km}$ with $B E R=0.014 \mathrm{sr}^{-1}$ corresponding to the urban aerosol type, suggesting the presence of polluted aerosols in the boundary layer. It must also be noted that the relative humidity shows a sharp minimum below $40 \%$ in this altitude range (Figure 8) which could contribute to decreasing $B E R$ of the aerosol trapped within PBL.

[39] Given the vertical aerosol extinction profile (Figure 7b), the column-averaged $B E R$ that we retrieve from the coupling between CALIOP and the Sun photometer $\left(0.026 \pm 0.02 \mathrm{sr}^{-1}\right)$ is controlled by the PBL aerosol. The two $B E R$ values proposed by the operational inversion scheme $(0.015$ and $0.050 \mathrm{sr}^{-1}$ ) in the PBL significantly differ from each other, but the $40-\mathrm{km}$ average is also significantly lower than $0.026 \mathrm{sr}^{-1}$. Such a difference explains the strong discrepancy in the aerosol extinction coefficient in the PBL shown in Figure 5a. The CALIOP operational algorithm did not assign the most correct aerosol model to the lowest layer, which is likely composed of a mixing between urban and marine aerosols. This may be due to errors associated with the weak AOT encountered and thus the weak SNR ( $\sim 7$ after smoothing) in the upper aerosol layer.

\subsection{Comparison to MODIS- and SEVERI-Derived AOT}

[40] Figure 9 shows the synoptic situation in terms of aerosol load and wind fields on 30 June, 2007. The mean AOTs over the study area derived from MODIS $(0.25 \pm 0.12$

Figure 9. Aerosol optical thicknesses at $550 \mathrm{~nm}\left(\tau_{a 550}\right)$ derived from MODIS and SEVERI for 30 June, 2007. (a) Terra/MODIS data (11:15 GMT) over land and MSG/ SEVERI daily mean data over sea; wind speeds are from the operational model of ECMWF with a horizontal resolution of $0.5^{\circ}$, at the level $700 \mathrm{hPa}$ at 00:00 GMT. (b) Same as Figure 9a but with data from Aqua/MODIS (12:45 GMT) and MSG/SEVERI (11:30 GMT), and 700-hPa wind field at 12:00 GMT. (c) The visible Angström exponent derived from SEVERI at 11:30 GMT superimposed with the wind fields at $950 \mathrm{hPa}$ at 12:00 GMT. The CALIPSO orbit is marked by the red solid line. at $550 \mathrm{~nm})$ over land, SEVERI $(0.24 \pm 0.05$ at $550 \mathrm{~nm})$ over sea, and the Sun photometer $(0.23 \pm 0.02$ at $500 \mathrm{~nm})$ are in good agreement (Table 1). The wind direction given in Figure 9 and CALIOP depolarization signal, although noisy, may let us suppose that desert air mass from Morocco contributes to the aerosol load over both the northeastern part of Spain and the southern part of France. Nevertheless, the AERONET Sun photometer of Barcelona shows an aerosol optical thickness of $\sim 0.22$ at $440 \mathrm{~nm}$ with a visible

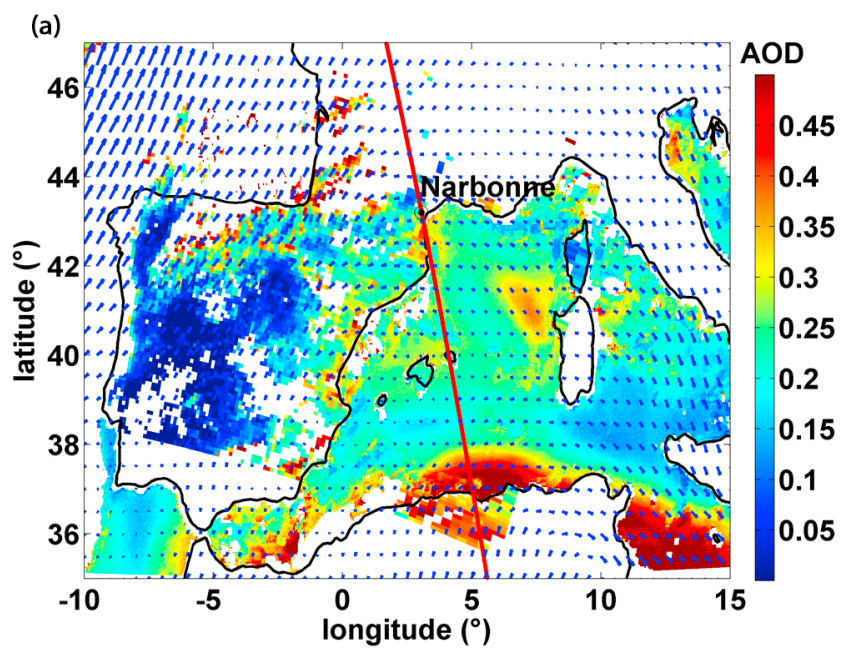

(b)

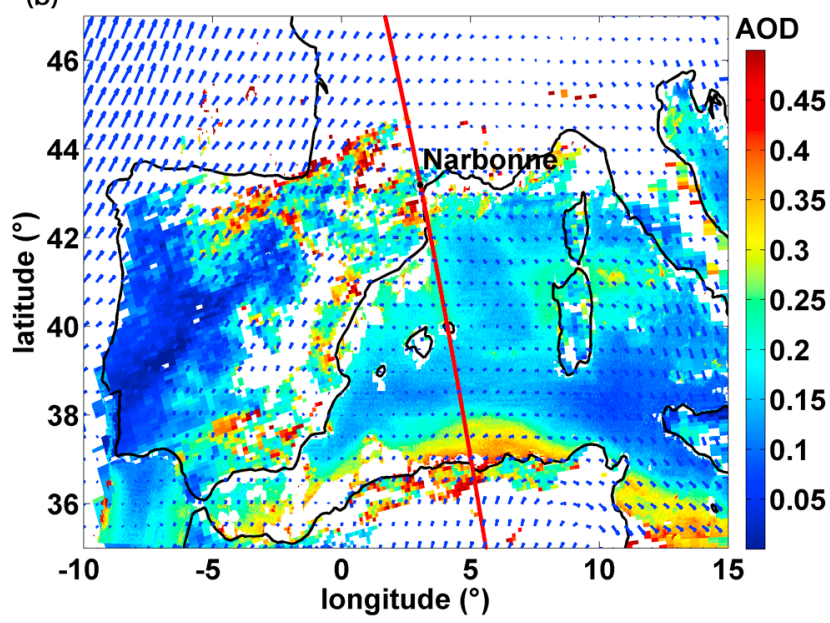

(c)

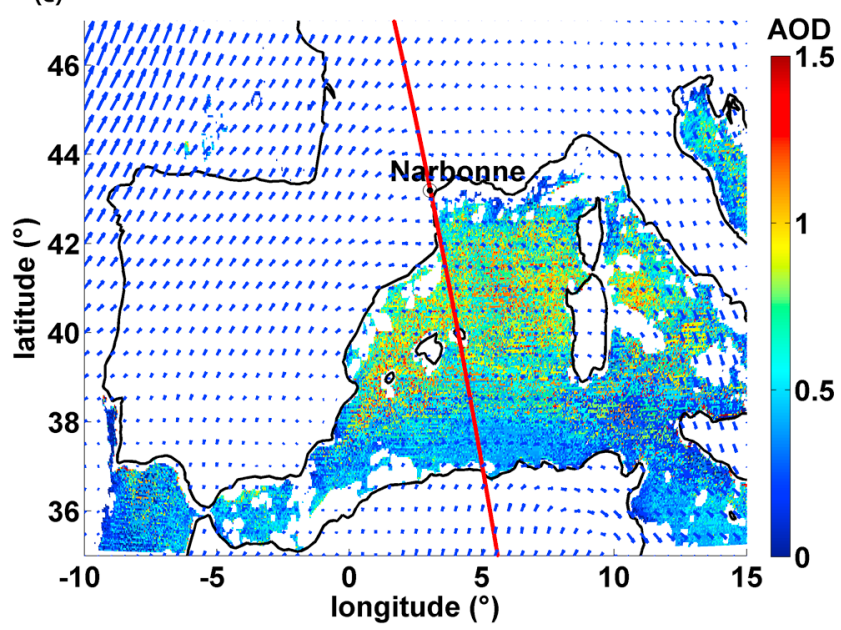


(a)

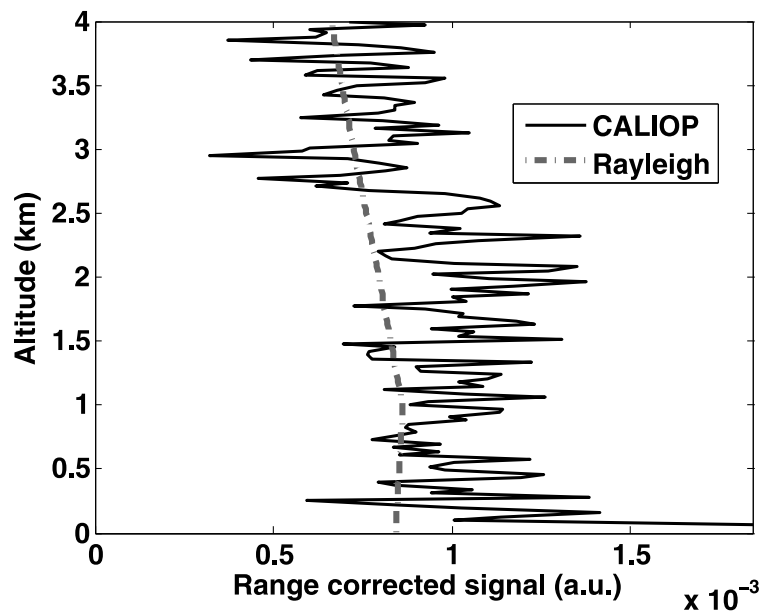

(c)

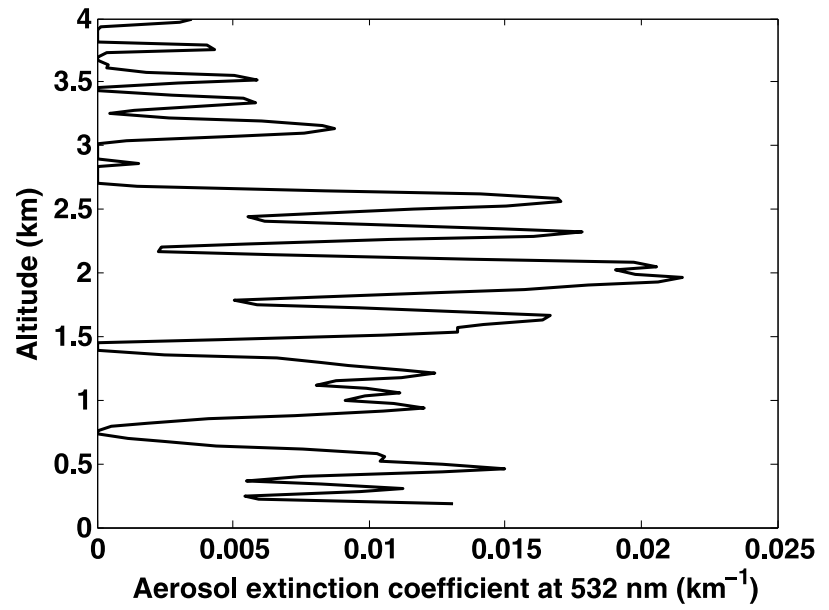

(b)

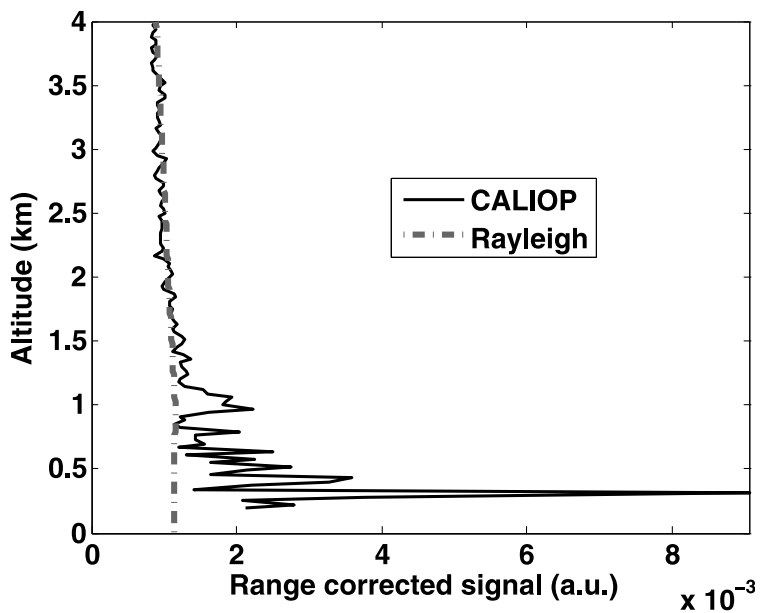

(d)

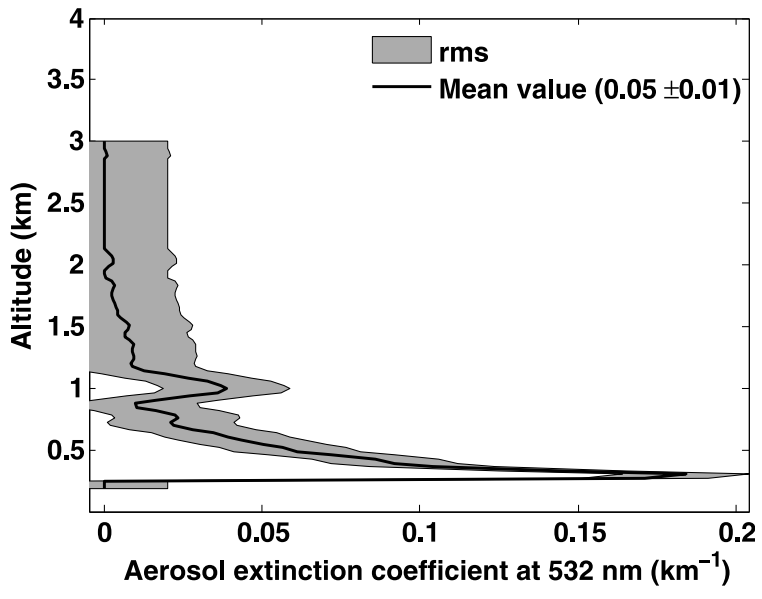

Figure 10. Range-corrected lidar signal of CALIOP during (a) daytime (23 June 2007) and (b) nighttime periods (6-7 July 2007) in presence of a very weak aerosol loading (averages of 337 and 440 profiles, respectively). The gray dash-dotted lines correspond to the molecular signal without aerosol presence (Rayleigh). The results of our own inversions of the mean profiles for (c) 23 June and (d) 6-7 July. The value of the aerosol optical thickness at $532 \mathrm{~nm}$ is given in parentheses.

Angström exponent of 1.65 , which is not characteristic of desert dust aerosols. The upper layer observed above Narbonne is thus likely a mixing of anthropogenic aerosol (fossil fuel burning and industrial dust). Moreover, no transport of African dust particles had been observed during the previous days by satellite or can be suspected from air mass backtrajectories (not shown).

[41] It is more likely that the upper layer of aerosol is related to a pollution event from the big cities and industrial centers located on the Iberian Peninsula. Note that the MODIS fire product does not show any source of biomass burning aerosol. The visible Angström exponent retrieved from SEVERI is close to 1 (Figure 9c and Table 1), in good agreement with the previous results, and confirms that the aerosol is not of desert origin.

\section{Observations in Clean Atmospheric Conditions}

[42] Two other coincidences with CALIPSO were explored in detail during our field experiment. They took place in clean atmospheric situations and can be regarded as an opportunity to evaluate the detection limits of CALIOP. The two situations differ since they correspond to daytime (23 June, 2007 12:55 GMT) and nighttime (7 July, 2007 02:00 GMT) conditions, respectively. The ground-based and airborne observations were located close to the aerodrome of Aubenas $\left(44^{\circ} 32^{\prime} \mathrm{N}, 4^{\circ} 22^{\prime} \mathrm{E}\right)$. Unfortunately, CALIPSO did not fly over the same topography in the two cases.

\subsection{Inversion of CALIOP Profiles}

[43] The numbers of averaged CALIOP profiles over the same valley are 440 and 337 for the daytime and nighttime orbits, respectively. Such values correspond to horizontal distances of 146 and $112 \mathrm{~km}$, respectively. The mean profiles of the range-corrected lidar signal are given in Figure 10 for the two cases in association with the corresponding profiles of the aerosol extinction coefficient at $532 \mathrm{~nm}$. No level-2 data is available for these two situations because the CALIOP layer detection scheme failed to detect any aerosol layer. Nevertheless, we performed the 


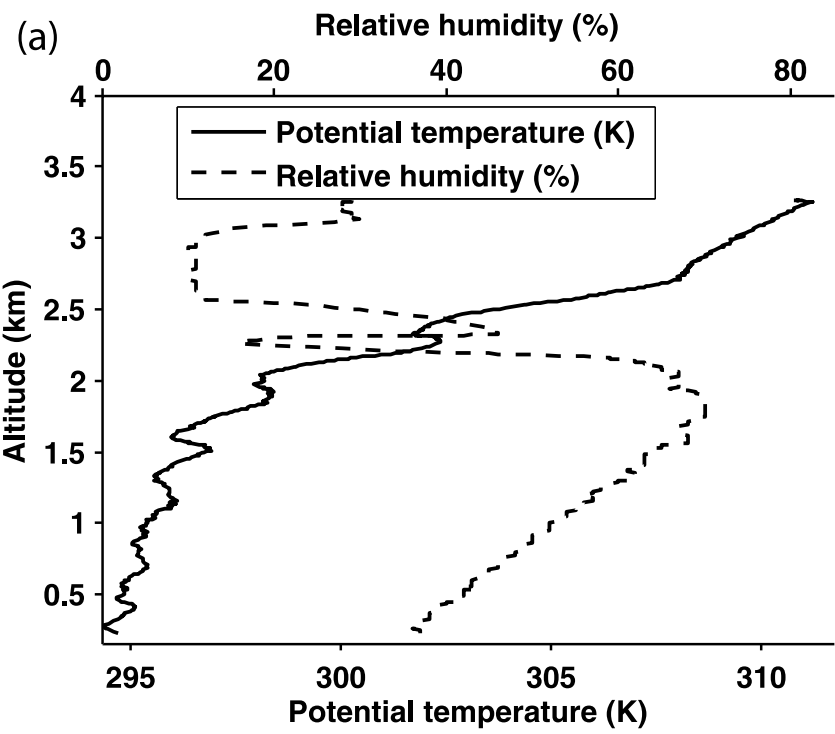

(b)

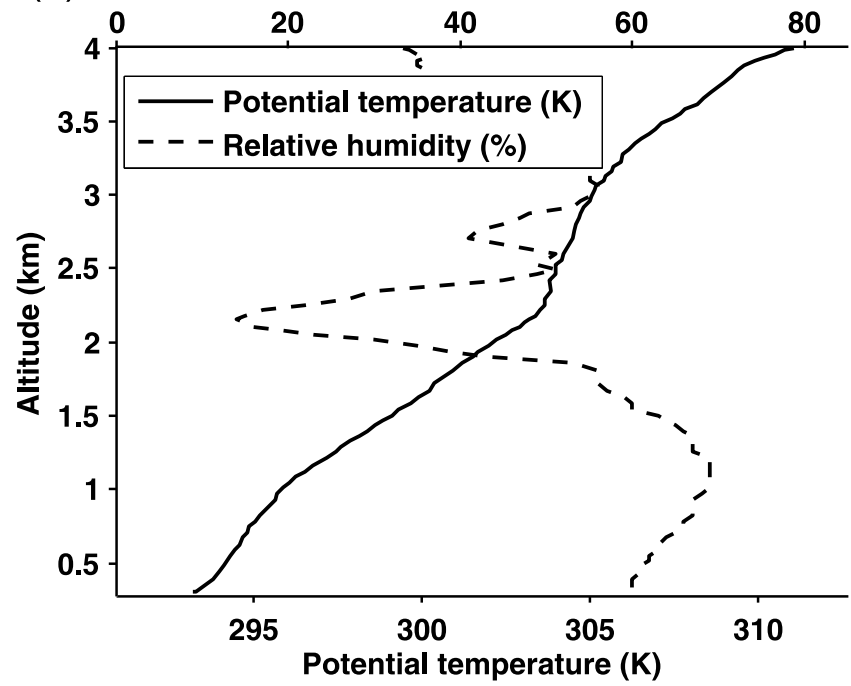

Figure 11. Vertical profiles of potential temperature and relative humidity acquired simultaneously to the lidar horizontal shooting aboard the ULA for (a) the daytime CALIOP measurement of 23 June 2007 and (b) the nighttime CALIOP measurements of 6-7 July 2007.

inversions after applying a low-pass frequency filter and using a $B E R$ value of $0.026 \mathrm{sr}^{-1}$, which is equal to that obtained in section 5 . The daytime profile (Figure 10c) tends to be very noisy and thus difficult to analyze. Uncertainties, including the mean variability, are such that they cannot be presented on the figure. Nevertheless, the top of a layer seems to appear close to $2.5 \mathrm{~km}$ AMSL, which may correspond to a shallow PBL. The inversion of such a layer to retrieve the aerosol extinction coefficient is not relevant because the lidar signal is too noisy. In the nighttime case (Figure 10d), a small aerosol layer could be observed below about $1 \mathrm{~km}$ AMSL, which corresponds to the stable atmospheric surface layer occurring at night. The resulting AOT is very low and equal to $0.05 \pm 0.01$ at $532 \mathrm{~nm}$. Such AOT is not surprising above this rural area remote from pollution sources.

\subsection{Ground-Based and Airborne Observations}

[44] Vertical profiles of $\theta_{w}$ and $R H$ shown in Figure 11 confirm the vertical structure of the lower troposphere. In particular, the top of the aerosol layer hardly observed on 23 June (Figure 10c) corresponds to the top of the PBL at $2 \mathrm{~km}$ AMSL. In spite of the high noise level, especially during the daytime case, CALIOP data are therefore able to identify the top of the PBL. Lidar and in situ measurements of the optical properties of the aerosols locate the layers at the same altitudes (Figure 12). The extinction coefficient is very low in these clean atmospheres, leading to optical thicknesses at $355 \mathrm{~nm}(880 \mathrm{~nm})$ of $0.11 \pm 0.01(0.06 \pm 0.01)$ and $0.07 \pm 0.01(0.02 \pm 0.01)$ on 23 June and on the night of 6-7 July, respectively. In daytime conditions the background sky radiance contribution acts to decrease CALIOP profile SNR from 15 (nighttime) to 6 (daytime) for the considered situations.

[45] Unfortunately, the ground-based lidar LESAA failed during the night of 6-7 July. Ground-based lidar data are only available on 23 June, 2007. The result of the inversion is given in Figure 13; the top of the PBL is close to $2 \mathrm{~km}$ with a similar aerosol extinction coefficient to that derived from the lidar onboard the ULA. The inversion has been performed here with the same $B E R$ value of $0.020 \mathrm{sr}^{-1}$ at $355 \mathrm{~nm}$ than on June 30. Clouds were present at the end of the experiment on 23 June and the nadir shooting observations from the ULA was not exploitable (see Figure 12c). This was not the case during the night of 6-7 July, 2007. As on 30 June, the consistency between the nadir and horizontal lidar shootings has been checked with $B E R=0.020 \mathrm{sr}^{-1}$ (Figure 14). Despite of the weak aerosol load, the lidar signals are in agreement and increase the confidence level on the quality of our measurements.

\subsection{Coherence With CALIOP Operational Products and Limitation}

[46] The previous layers have not been detected from the vertical feature mask (VFM) algorithm of the operational treatment. Hence, no comparison was possible in terms of either vertical structures or aerosol optical properties. Such limitation could be due to the CALIOP's minimum detectable backscatter coefficient. This threshold value has been calculated for daytime and nighttime conditions by Vaughan et al. [2004] and McGill et al. [2007]. For a vertical resolution of $60 \mathrm{~m}$ they give values of $9.6810^{-4}$ and $7.5010^{-4} \mathrm{~km}^{-1} \mathrm{sr}^{-1}$ at $532 \mathrm{~nm}$ in the PBL, respectively. In the clean conditions presented in this paper, the backscatter coefficient is close to $810^{-4} \mathrm{~km}^{-1} \mathrm{sr}^{-1}$. It is thus normal that the operational algorithm does not give any information on those layers. Their extinction levels are close to the detection limit.

\section{Conclusions}

[47] This work presents the results of an original field experiment dedicated to the validation of the spaceborne lidar instrument CALIOP onboard the satellite CALIPSO. The analysis of relatively clear-sky daytime and nighttime 
(a)

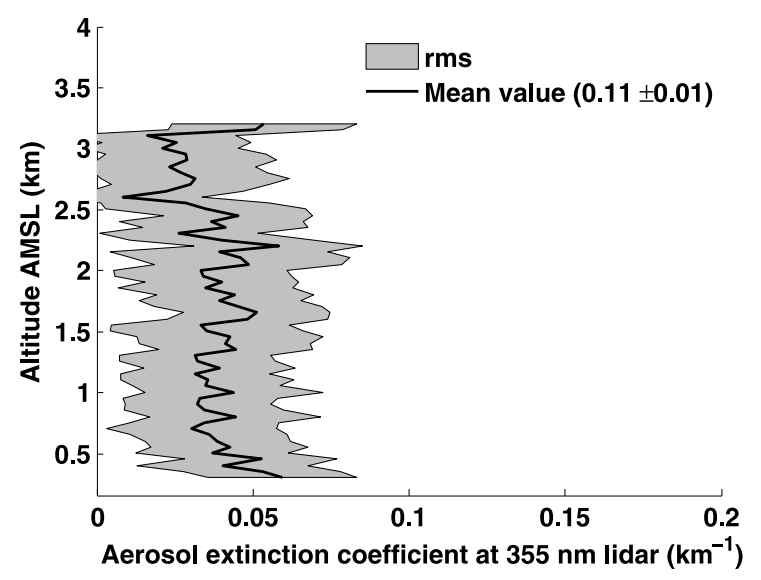

(c)

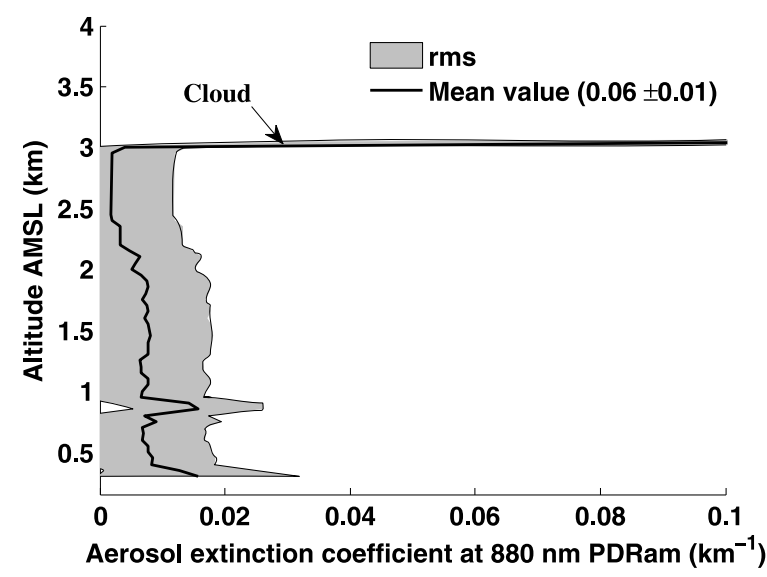

(b)

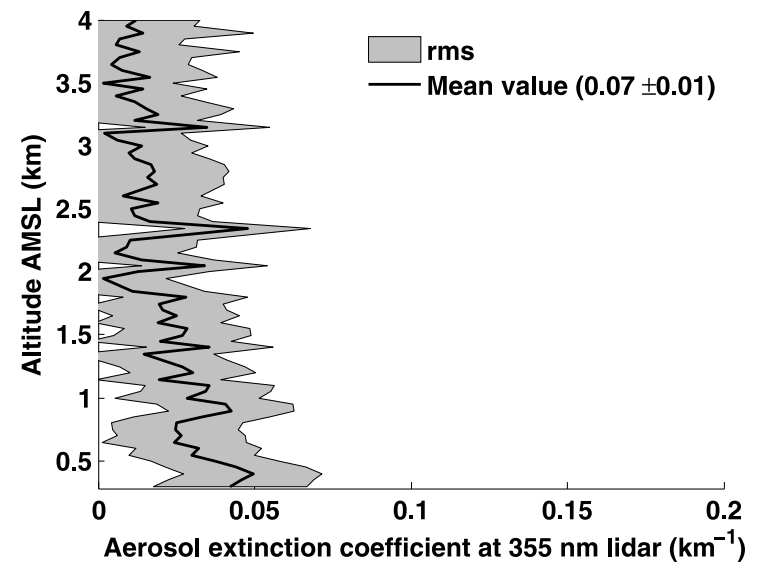

(d)

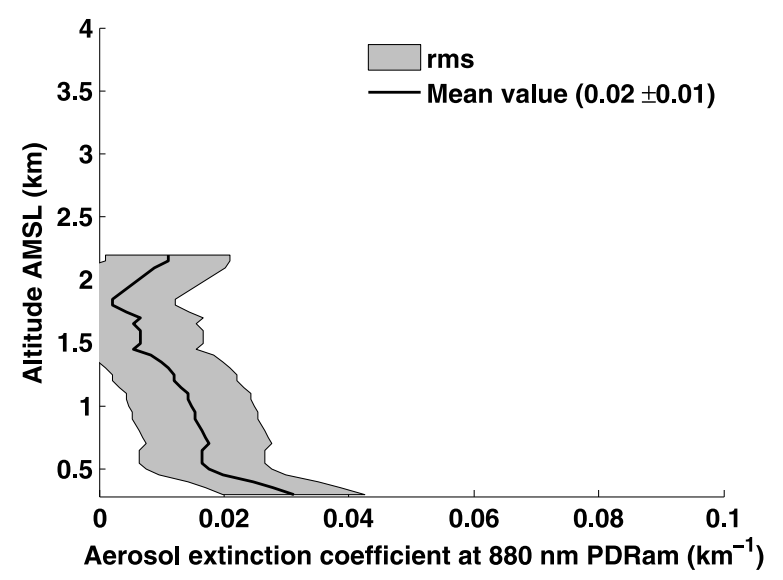

Figure 12. Vertical profiles of the aerosol extinction coefficient at $355 \mathrm{~nm}$ retrieved from horizontal lidar shooting on (a) 23 June 2007 and (b) during the night of 6-7 July 2007. Values at $880 \mathrm{~nm}$ derived from the PDRam in situ instrument for (c) 23 June 2007 and (d) during the night of 6-7 July 2007. The aerosol optical thickness is given in parentheses with its temporal variability.

cases indicates that CALIOP is able to locate scattering layers having weak aerosol loads $\left(\tau_{a 532} \sim 0.1\right)$ in the lower troposphere. When the aerosol loads are higher $(\sim 0.20$ $0.25)$, an agreement was demonstrated for the AOT derived from our lidar and in situ observations, our inversion of CALIOP profiles, and MODIS and SEVERI operational products. The choice of the BER was constrained by photometric measurements and was supported by independent results from a specific strategy of coupled airborne lidar measurements in horizontal and vertical shooting configurations. When the comparison is made with the CALIOP level-2 products, at the first order, the agreement should be regarded as reasonable when comparing $B E R$ values. In the PBL, the likely value of $0.026 \pm 0.002 \mathrm{sr}^{-1}$ is included in the broad range of the values derived from the operational algorithm (0.015 and $\left.0.050 \mathrm{sr}^{-1}\right)$. Nevertheless, the BER selected by the operational algorithm does not seem in agreement with the actual aerosol model encountered. That leads to an overestimation by a factor of $\sim 2$ of the aerosol extinction coefficient in the PBL.

[48] The results of this work, although based on a limited number of cases for situations of weak and medium aerosol

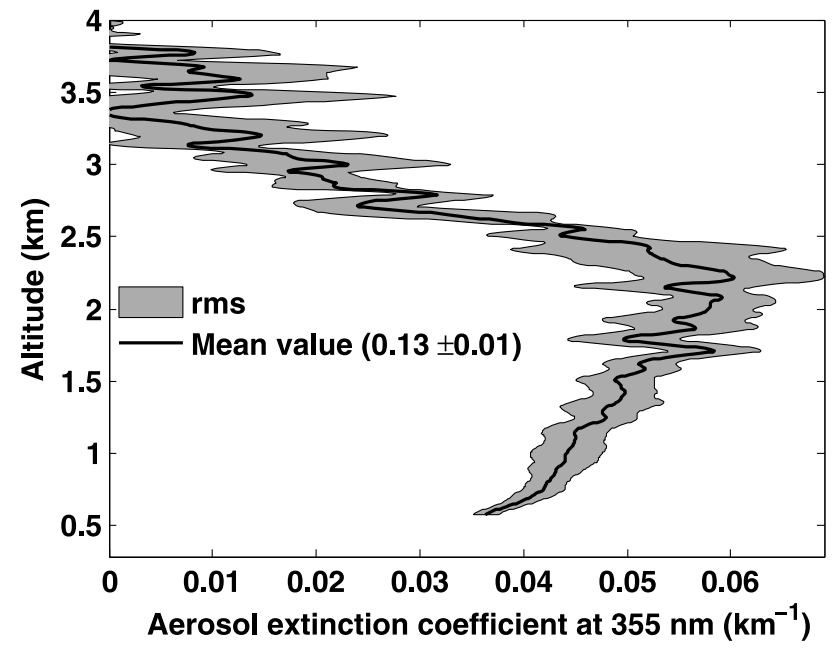

Figure 13. Aerosol vertical extinction coefficient retrieved from LESAA lidar on 23 June 2007. The gray area represents the temporal variability for $\pm 20 \mathrm{~min}$ around the CALIPSO overflight. The aerosol optical depth and its temporal variability are given in parentheses. 


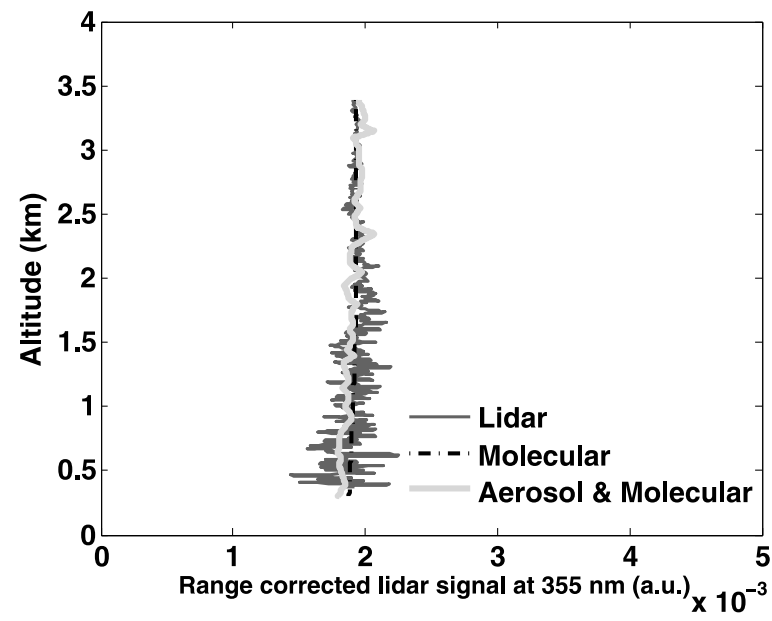

Figure 14. Consistency between the simulation of lidar profiles and measurements on the night of 6-7 July 2007. The black dash-dotted line gives the contribution of the molecular scattering alone.

loads, show that CALIOP is able to provide information on the structure of aerosol layers with optical thicknesses lower than 0.3 at the wavelength of $532 \mathrm{~nm}$. The lower limit seems located under 0.07 during night and 0.1 during day. The inversion of the lidar profiles remains of good quality for AOT $\sim 0.2$ at $532 \mathrm{~nm}$ with horizontal resolutions of $\sim 40 \mathrm{~km}$. Studies on the pollution of great urban centers and megapoles using CALIOP observations appear feasible when significant pollution occurs.

[49] Acknowledgments. This work was supported by the Centre National d'Etudes Spatiales (CNES) and the Commissariat à l'Energie Atomique (CEA). We especially thank the ULA pilot Franck Toussaint for his contribution. The ULA Air Creation Company and the airfield authorities of Narbonne-Vinassan are acknowledged for their logistical help. We thank Bryan Baum, from the SSEC laboratory, University of Wisconsin-Madison, for proofreading the manuscript and for giving valuable comments.

\section{References}

Anselmo, T., et al. (2005), Cloud-Aerosol LIDAR Infrared Pathfinder Satellite Observations data management system, data products catalog, Rep. PC-SCI-503, NASA Langley Res. Cent., Hampton, Va. (Available at http://www-calipso.larc.nasa.gov/resources/project_documentation. php)

Ansmann, A. (2006), Ground-truth aerosol lidar observations: Can the Klett solutions obtained from ground and space be equal for the same aerosol case?, Appl. Opt., 45, 3367-3371, doi:10.1364/AO.45.003367.

Ben-Ami, I., Y. Koren, and O. Altaratz (2009), Patterns of North African dust transport over the Atlantic: Winter vs. summer, based on CALIPSO first year data, Atmos. Chem. Phys., 9, 7867-7875, doi:10.5194/acp-97867-2009.

Berthier, S., P. Chazette, P. Couvert, J. Pelon, F. Dulac, F. Thieuleux, C. Moulin, and T. Pain (2006), Desert dust aerosol columnar properties over ocean and continental Africa from Lidar in-Space Technology Experiment (LITE) and Meteosat synergy, J. Geophys. Res., 111, D21202, doi:10.1029/2005JD006999.

Bucholtz, A. (1995), Rayleigh-scattering calculations for the terrestrial atmosphere, Appl. Opt., 34, 2765-2773, doi:10.1364/AO.34.002765.

Chazette, P. (2003), The monsoon aerosol extinction properties at Goa during INDOEX as measured with lidar, J. Geophys. Res., 108(D6), 4187, doi:10.1029/2002JD002074.

Chazette, P., C. David, J. Lefrère, S. Godin, J. Pelon, and G. Mégie (1995), Comparative lidar study of the optical, geometrical, and dynamical properties of stratospheric post-volcanic aerosols, following the eruption of
El Chichon and Mount Pinatubo, J. Geophys. Res., 100(D11), 23,19523,207, doi:10.1029/95JD02268.

Chazette, P., H. Randriamiarisoa, J. Sanak, P. Couvert, and C. Flamant (2005a), Optical properties of urban aerosol from airborne and groundbased in situ measurements performed during the ESQUIF program, J. Geophys. Res., 110, D02206, doi:10.1029/2004JD004810.

Chazette, P., P. Couvert, H. Randriamiarisoa, J. Sanak, B. Bonsang, P. Moral, S. Berthier, S. Salanave, and F. Toussaint (2005b), Threedimensional survey of pollution during winter in French Alps valleys, Atmos. Environ., 39, 1035-1047, doi:10.1016/j.atmosenv.2004.10.014.

Chazette, P., J. Sanak, and F. Dulac (2007), New approach for aerosol profiling with a lidar onboard an ultralight aircraft: Application to the African Monsoon Multidisciplinary Analysis, Environ. Sci. Technol., 41, 83358341, doi:10.1021/es070343y.

Cuesta, J., et al. (2008), Multi-platform observations of the seasonal evolution of the Saharan atmospheric boundary layer in Tamanrasset, Algeria, in the framework of the African Monsoon Multidisciplinary Analysis field campaign conducted in 2006, J. Geophys. Res., 113, D00C07, doi:10.1029/2007JD009417.

Dulac, F., P. Chazette, L. Gomes, B. Chatenet, H. Berger, and J. M. Vinicula dos Santos (2001), A method for aerosol profiling in the lower troposphere with coupled scatter and meteorological rawindsondes and first data from the tropical Atlantic off Sahara, J. Aerosol Sci., 32, 1069-1086, doi:10.1016/S0021-8502(01)00043-X.

Ganguly, D., P. Ginoux, V. Ramaswamy, D. M. Winker, B. N. Holben, and S. N. Tripathi (2009), Retrieving the composition and concentration of aerosols over the Indo-Gangetic basin using CALIOP and AERONET data, Geophys. Res. Lett., 36, L13806, doi:10.1029/2009GL038315.

Hamonou, E., P. Chazette, D. Balis, F. Dulac, X. Schneider, E. Galani, G. Ancellet, and A. Papayannis (1999), Characterisation of the vertical structure of Saharan dust export to the Mediterranean bassin, J. Geophys. Res., 104(D18), 22,257-22,270, doi:10.1029/1999JD900257.

Hodzic, A., R. Vautard, H. Chepfer, P. Goloub, L. Menut, P. Chazette, J. L. Deuzé, A. Apituley, and P. Couvert (2006), Evolution of aerosol optical thickness over Europe during the August 2003 heat wave as seen from CHIMERE model simulations and POLDER data, Atmos. Chem. Phys., 5, 4115-4141.

Holben, B. N., et al. (1998), AERONET-A federated instrument network and data archive for aerosol characterisation, Remote Sens. Environ., 66, 1-16, doi:10.1016/S0034-4257(98)00031-5.

Hostetler, C. A., Z. Liu, J. Reagan, M. Vaughan, D. Winker, M. Osborn, W. H. Hunt, K. A. Powell, and C. Trepte (2005), CALIOP algorithm theoretical basis document-Part 1: Lidar level I ATBD-Calibration and level 1 data products, Rep. PC-SCI-201, NASA Langley Res. Cent., Hampton, Va. (Available at http://www-calipso.larc.nasa.gov/resources/ project documentation.php)

Hunt, W. H., D. M. Winker, M. A. Vaughan, K. A. Powell, P. L. Lucker, and C. Weimer (2009), CALIPSO Lidar Description and Performance Assessment, J. Atmos. Oceanic Technol., 26, 1214-1228, doi:10.1175/ 2009JTECHA1223.1.

Jeong, M.-J., and N. C. Hsu (2008), Retrievals of aerosol single-scattering albedo and effective aerosol layer height for biomass-burning smoke: Synergy derived from “A-Train” sensors, Geophys. Res. Lett., 35, L24801, doi:10.1029/2008GL036279.

Kim, S. W., S. Berthier, J.-C. Raut, P. Chazette, F. Dulac, and S.-C. Yoon (2008), Validation of aerosol and cloud layer structures from the spaceborne lidar CALIOP using a ground-based lidar in Seoul, Korea, Atmos. Chem. Phys., 8, 3705-3720, doi:10.5194/acp-8-3705-2008.

Klett, J. D. (1981), Stable analytical inversion solution for processing lidar returns, Appl. Opt., 20, 211-220, doi:10.1364/AO.20.000211.

Klett, J. D. (1985), Lidar inversion with variable backscatter/extinction ratios, Appl. Opt., 24, 1638-1643, doi:10.1364/AO.24.001638.

Labonne, M., F.-M. Bréon, and F. Chevallier (2007), Injection height of biomass burning aerosols as seen from a spaceborne lidar, Geophys. Res. Lett., 34, L11806, doi:10.1029/2007GL029311.

Liu, Z., A. H. Omar, Y. Hu, M. A. Vaughan, and D. M. Winker (2005), CALIOP algorithm theoretical basis document-Part 3: Scene classification algorithms, Rep. $P C-S C I-202.03$, NASA Langley Res. Cent., Hampton, Va. (Available for download at http:/www-calipso.larc.nasa. gov/resources/project_documentation.php)

Liu, Z., et al. (2008), CA $\bar{A} L I P S O$ lidar observations of the optical properties of Saharan dust: A case study of long-range transport, J. Geophys. Res., 113, D07207, doi:10.1029/2007JD008878.

Lyamania, H., F. J. Olmoa, A. Alcántaraa, and L. Alados-Arboledasa (2006), Atmospheric aerosols during the 2003 heat wave in southeastern Spain II: Microphysical columnar properties and radiative forcing, Atmos. Environ., 40, 6465-6476, doi:10.1016/j.atmosenv.2006.04.047.

McGill, M. J., M. A. Vaughan, C. R. Trepte, W. D. Hart, D. L. Hlavka, D. M. Winker, and R. Kuehn (2007), Airborne validation of spatial prop- 
erties measured by the CALIPSO lidar, J. Geophys. Res., 112, D20201, doi:10.1029/2007JD008768.

Measures, R. M. (1984), Laser Remote Sensing, edited by Wiley-Intersci., Hoboken, N. J.

Mona, L., A. Amodeo, A. Boselli, G. D’Amico, A. Giunta, F. Madonna, F. Russo, and G. Pappalardo (2009), One year of CNR-IMAA multiwavelength Raman lidar measurements in correspondence of CALIPSO overpass: Level 1 products comparison, Atmos. Chem. Phys. Discuss., 9, 8429-8468, doi:10.5194/acpd-9-8429-2009.

Nicolet, M. (1984), On the molecular scattering in the terrestrial atmosphere, Planet. Space Sci., 32, 1467-1468, doi:10.1016/0032-0633(84) 90089-8.

Omar, A. H., et al. (2009), The CALIPSO automated aerosol classification and lidar ratio selection algorithm, J. Atmos. Oceanic Technol., 26, 1994-2014, doi:10.1175/2009JTECHA1231.1.

Pappalardo, G., et al. (2010), EARLINET correlative measurements for CALIPSO: First intercomparison results, J. Geophys. Res., 115, D00H19, doi:10.1029/2009JD012147.

Platt, C. M. R. (1973), Lidar and radiometric observation of cirrus clouds, J. Atmos. Sci., 30, 1191-1204, doi:10.1175/1520-0469(1973)030<1191: LAROOC $>2.0 . \mathrm{CO} ; 2$.

Platt, C. M. R. (1981), Remote sensing of high clouds III. Monte Carlo calculations of multiply scattered lidar returns, J. Atmos. Sci., 38, 156-167, doi:10.1175/1520-0469(1981)038<0156:RSOHCI >2.0.CO;2.

Powell, K. A., M. A. Vaughan, R. Kuehn, W. H. Hunt, and K.-P. Lee (2008), Revised calibration strategy for the CALIOP 532-nm channel: Part II-Daytime, paper presented at 24th International Laser Radar Conference, Natl. Cent. For Atmos. Res., Boulder, Colo.

Powell, K. A., et al. (2009), CALIPSO lidar calibration algorithms: Part I-Nighttime $532 \mathrm{~nm}$ parallel channel and $532 \mathrm{~nm}$ perpendicular channel, J. Atmos. Oceanic Technol., 26, 2015-2033, doi:10.1175/ 2009JTECHA1242.1.

Raut, J.-C., and P. Chazette (2008a), Vertical profiles of urban aerosol complex refractive index in the frame of ESQUIF airborne measurements, Atmos. Chem. Phys., 8, 901-919, doi:10.5194/acp-8-901-2008.

Raut, J.-C., and P. Chazette (2008b), Radiative budget in the presence of multi-layered aerosol structures in the framework of AMMA SOP-0, Atmos. Chem. Phys., 8, 6839-6864, doi:10.5194/acp-8-6839-2008.

Raut, J.-C., and P. Chazette (2009), Assessment of vertically resolved PM10 from mobile lidar observations, Atmos. Chem. Phys. Discuss., 9 , 13,475-13,521, doi:10.5194/acpd-9-13475-2009.
Remer, L. A., et al. (2005), The MODIS aerosol algorithm, products and validation, J. Atmos. Sci., 62, 947-973, doi:10.1175/JAS3385.1.

Salomonson, V. V., et al. (1989), MODIS: Advanced facility instrument for studies of the Earth as a system, IEEE Trans. Geosci. Remote Sens., 27, 145-153, doi:10.1109/36.20292.

Spinhirne, J. D. (1982), Lidar clear atmosphere multiple scattering dependence on receiver range, Appl. Opt., 21, 2467-2468, doi:10.1364/ AO.21.002467.

Thieuleux, F., C. Moulin, F.-M. Bréon, F. Maignan, J. Poitou, and D. Tanré (2005), Remote sensing of aerosols over the oceans using MSG/SEVIRI Imagery, Ann. Geophys., 23(12), 3561-3568.

Uno, I., K. Yumimoto, A. Shmizu, Y. Hara, N. Sugimoto, Z. Wang, Z. Liu, and D. M. Winker (2008), 3D structure of Asian dust transport revealed by CALIPSO lidar and a 4DVAR dust model, Geophys. Res. Lett., 35, L06803, doi:10.1029/2007GL032329.

Vaughan, M. A., S. A. Young, D. M. Winker, K. A. Powell, A. H. Omar, Z. Liu, Y. Hu, and C. A. Hostetler (2004), Fully automated analysis of space-based lidar data: An overview of the CALIPSO retrieval algorithms and data products, Proc. SPIE Int. Soc. Opt. Eng., 5575, 16-30, doi:10.1117/12.572024.

Winker, D. (2003), Accounting for multiple scattering in retrievals from space lidar, Proc. SPIE Int. Soc. Opt. Eng., 5059, 128-139.

Winker, D. M., W. H. Hunt, and C. A. Hostetler (2004), Status and performance of the CALIOP lidar, Proc. SPIE Int. Soc. Opt. Eng., 5575, 8-15.

Winker, D. M., W. H. Hunt, and M. J. McGill (2007), Initial performance assessment of CALIOP, Geophys. Res. Lett., 34, L19803, doi:10.1029/ 2007GL030135.

Young, S.A., and M. A. Vaughan (2009), The retrieval of profiles of particulate extinction from Cloud-Aerosol Lidar Infrared Pathfinder Satellite Observations (CALIPSO) data: Algorithm description, J. Atmos. Oceanic Technol., 26, 1105-1119, doi:10.1175/2008JTECHA1221.1.

S. Berthier, P. Chazette, F. Dulac, H. Grigaut-Desbrosses, S.-W. Kim, S. Loaëc, P. Royer, and J. Sanak, Laboratoire des Sciences du Climat et de l'Environnement, CEA, CNRS, UVSQ, F-91191 Gif-sur-Yvette, France. (patrick.chazette@cea.fr)

J.-C. Raut, Laboratoire Atmosphères, Milieux, Observations Spatiales, CNRS, UVSQ, UPMC, Université Paris 6, F-72252 Paris, France. 